\title{
Reconstruction of biological drought conditions during the past 2847 years in an alpine environment of the northeastern Tibetan Plateau, China, and possible linkages to solar forcing
}

\author{
Zhi-Yong Yin ${ }^{\mathrm{a}, \mathrm{b}}$, Haifeng Zhu ${ }^{\mathrm{c}, \mathrm{e}}$, Lei Huang ${ }^{\mathrm{d}}$, Xuemei Shao ${ }^{\mathrm{a}, \mathrm{e}, *}$ \\ a Key Laboratory of Land Surface Pattern and Simulation, Institute of Geographic Sciences and Natural Resources Research, Chinese Academy of Sciences, Beijing 100101, PR China \\ b Environmental and Ocean Sciences, University of San Diego, 5998 Alcala Park, San Diego, CA 92110, USA \\ c Institute of Tibetan Plateau Research, Chinese Academy of Sciences, Beijing 100101, PR China \\ d National Climate Center, China Meteorological Administration, Beijing 100081, PR China \\ e Chinese Academy of Sciences, Center for Excellence in Tibetan Plateau Earth System Sciences, Beijing 100101, PR China
}

\section{A R T I C L E I N F O}

\section{Article history:}

Received 1 October 2015

Received in revised form 29 April 2016

Accepted 30 April 2016

Available online 3 May 2016

\section{Keywords:}

Tree ring widths

Droughts

Northeastern Tibetan Plateau

Water balance modeling

\begin{abstract}
A B S T R A C T
In this study we reconstructed the moisture condition of the eastern Qaidam Basin of the northeastern Tibetan Plateau based on a 3585-year tree ring chronology. The growth environment of Qilian juniper (Sabina przewalskii Kom.) on the mountains in the eastern Qaidam Basin was first determined by comparing precipitation and temperature estimates from two spatial datasets (PRISM and World Climate). Moisture balance was calculated as the sum of simulated moisture deficit (negative) and surplus using a modified Thornthwaite water balance model, and used as a proxy of biological drought conditions. Using data during 1956-2005, we established the transfer function to reconstruct a 2847-year series of January-June moisture balance ( $843 \mathrm{BCE}-2004 \mathrm{CE}$ ). With an adjusted $\mathrm{R}^{2}$ value of 0.654 of the transfer function and strong performance in validation, the reconstructed JanuaryJune moisture balance can be considered an excellent indicator of biological drought conditions for the study region. The reconstructed series showed strong correlations with reconstructed PDSI in the monsoon Asian region, representing a region of $10^{\circ}$ latitudes by $20^{\circ}$ longitudes. Using the reconstructed series, we identified centennialscale dry periods since 843 BCE: 381-277 BCE, 425-520 CE, 1108-1212 CE, 1428-1516 CE, and 1634-1743 CE. Additionally it had statistically significant negative correlations with a monsoon intensity proxy based on oxygen stable isotope from southwestern China (Dongge Cave). Further analyses identified significant relationships with solar activity, especially during the last 700 years. We confirmed the $\sim 200$-year cyclic pattern in the reconstructed moisture balance series, which matched the known 210-year de Vries solar cycle and peaked during the Little Ice Age. However, the cyclic patterns of the reconstructed moisture balance series and solar activity were decoupled for the period prior to approx. $1300 \mathrm{CE}$.
\end{abstract}

(c) 2016 Elsevier B.V. All rights reserved.

\section{Introduction}

Studies of megadroughts in the past have attracted much attention in recent years (e.g., Cook et al., 2010a, 2010b; Routson et al., 2011; Sinha et al., 2011; Stahle et al., 2007). Assessments on the severity and frequency of occurrence of such events require long records of climatic conditions as the context, especially when variation patterns on the multi-decadal and centennial time-scales are investigated. Among the most widely used proxies of past climate, tree ring data provide information of various aspects of climate at the annual resolution (Fritts, 1976; Hughes, 2011) and millennium-length records have been found in the northeastern Tibetan Plateau (Shao et al., 2005; Sheppard et al.,

\footnotetext{
* Corresponding author at: A11 Datun Road, Chaoyang District, Beijing 100101, PR China.

E-mail address: shaoxm@igsnrr.ac.cn (X. Shao).
}

2004; Zhang et al., 2003; Yang et al., 2014). The Tibetan Plateau is a region of great significance in regards of climate change. On the one hand, its mechanical and thermal dynamic effects on atmospheric circulation have far-reaching influences on the Asian monsoons (Wu et al., 2007; Yanai and Li, 1994; Yanai et al., 1992; Yeh and Gao, 1979). On the other hand, the Plateau has been regarded as a region highly sensitive to climatic change and is experiencing or will experience significant environmental changes associated with the recent warming, from atmospheric and hydrological processes (e.g., Liu and Chen, 2000; Liu et al., 2006; Wang et al., 2008; Zhao et al., 2004) to vegetation cover (e.g., Wang et al., 2011; Zhao et al., 2011) and cryosphere (Cheng and Wu, 2007; Li et al., 2008; Yao et al., 2007).

The conventional approach of using tree ring data to reconstruction of past climate is to select sampling sites with consideration of the target climatic variable for reconstruction, and then to use the instrumental data from near-by weather stations to build the transfer functions 
during the calibration period (Fritts, 1976). In some cases, however, the climatic conditions at the sampling sites can be quite different from those at the weather stations. For example, in semi-arid regions, sampling sites are often found on mountain slopes with elevations higher than the near-by weather stations and tend to have much wetter and cooler conditions than the weather stations located on the valley bottoms or foothills. Such differences in micro-environments often lead to different climatic elements to act as the limiting factors of tree growth (Fritts, 1976). When temporal variation patterns are concerned, strong associations between the tree ring data and observed climatic conditions at the near-by weather stations may indicate commonalities in regional climatic conditions, even though the exact growth conditions at the tree ring sampling sites may be quite different from the environments represented by the weather stations.

Of the moisture sensitive Qilian juniper (S. przewalskii Kom.) ringwidth chronologies found in the eastern Qaidam Basin of the northeastern Tibetan Plateau, a common feature in the relationships between tree growth and climate variables is a strong positive correlation with precipitation in the late spring and early summer (esp. May and/or June) in conjunction with a negative correlation with temperature for the same time period (e.g., Shao et al., 2010; Shao et al., 2005; Sheppard et al., 2004; Yin et al., 2008; Zhang et al., 2003). This has also been discovered for a variety of coniferous species in other areas of the northeastern and eastern Tibetan Plateau, such as Qilian Mountains (Zhang et al., 2011, in May-June, approx. $38.81-39.04^{\circ} \mathrm{N}, 99.96-100.81^{\circ} \mathrm{E}$ ) to the north, and Yushu (Qin et al., 2003; Shi et al., 2010), Anyemaqen Mountains (Peng et al., 2007), Changdu (Zhu et al., 2011), and central Hengduan Mountains (Fan et al., 2009) south of the eastern Qaidam Basin. Since the temperature during the early growing season would rarely reach the harmful levels for physiological processes at the sampling sites with elevations typically higher than $3000 \mathrm{~m}$ above sea level (a.s.l.) in these areas, strong negative correlations between tree growth and temperature indicate the effects of enhanced water-use demand under relatively warm conditions during the early growing season. This phenomenon should be particularly prominent for trees growing on steep slopes with shallow and well-drained soils and with exposure to strong wind (Fritts, 1976), which are typical of the alpine environments in the semi-arid northeastern Tibetan Plateau. In other words, early growing-season moisture condition can be considered as the ultimate factor regulating tree growth in this region. In an earlier study (Yin et al., 2008), it was found that the simulated moisture conditions in the eastern Qaidam Basin (Delingha) using a water balance model were strongly correlated with the radial growth of Qilian juniper, outperforming similar analyses using precipitation or Palmer's Drought Severity Index (PDSI, Palmer, 1965) data. However, whether the simulated moisture variables (e.g., soil moisture, and moisture deficit and surplus) represented the conditions at the weather station on the foothills or those at the tree ring sampling sites was a question unanswered.

Without in situ observational data, it is difficult to quantify the growth environments and moisture conditions at the sampling sites. For the eastern Qaidam Basin, the climatic conditions recorded at the weather stations, with mean annual total precipitation close to $200 \mathrm{~mm}$ (e.g., $177 \mathrm{~mm} /$ year for Delingha and $203 \mathrm{~mm}$ /year in Dulan for the period 1971-2000), are characteristic of a semi-arid region. Such climatic condition is favorable for the desert and steppe vegetation (Woodward et al., 2004) and cannot support a forest vegetation in the foothills areas of the eastern Qaidam Basin (Zheng, 1996). For the general region of the northeastern Tibetan Plateau, Wu (1990) showed that the maximum precipitation occurred at the station Jiuzhi $\left(33^{\circ} 26^{\prime}\right.$ $\mathrm{N}, 101^{\circ} 29^{\prime} \mathrm{E}, 3629 \mathrm{~m}$ a.s.l.), compared to 4 other stations with elevations ranging from $3414 \mathrm{~m}$ (Waisi at $34^{\circ} 12^{\prime} \mathrm{N}, 101^{\circ} 34^{\prime} \mathrm{E}$ ) to $4211 \mathrm{~m}$ (Maqin at $34^{\circ} 16^{\prime} \mathrm{N}, 99^{\circ} 12^{\prime} \mathrm{E}$ ). So elevation cannot be the only factor that determines precipitation distribution at the regional scale. At a smaller scale, however, the differences in elevation and long-term mean precipitation (1971-2000) between two nearby weather stations (Tianjun at $37^{\circ} 18^{\prime}$ $\mathrm{N}, 99^{\circ} 02^{\prime} \mathrm{E}$ vs. Chaka at $36^{\circ} 47^{\prime} \mathrm{N}, 99^{\circ} 05^{\prime} \mathrm{E}$, approximately $60 \mathrm{~km}$ apart, Fig. 1) allowed us to obtain a precipitation gradient of $42 \mathrm{~mm} / 100 \mathrm{~m}$ (345 mm/year at Tianjun at $3417 \mathrm{~m}$ vs. $208 \mathrm{~mm} / \mathrm{year}$ at Chaka at $3088 \mathrm{~m}$ ). Based on the elevation differences ( $700 \mathrm{~m}$ or more) between the weather station in Delingha and our sampling sites, there should be a minimum increase of $294 \mathrm{~mm}$ in annual precipitation to $471 \mathrm{~mm} /$ year. In other words, precipitation at the sampling sites in Delingha might be

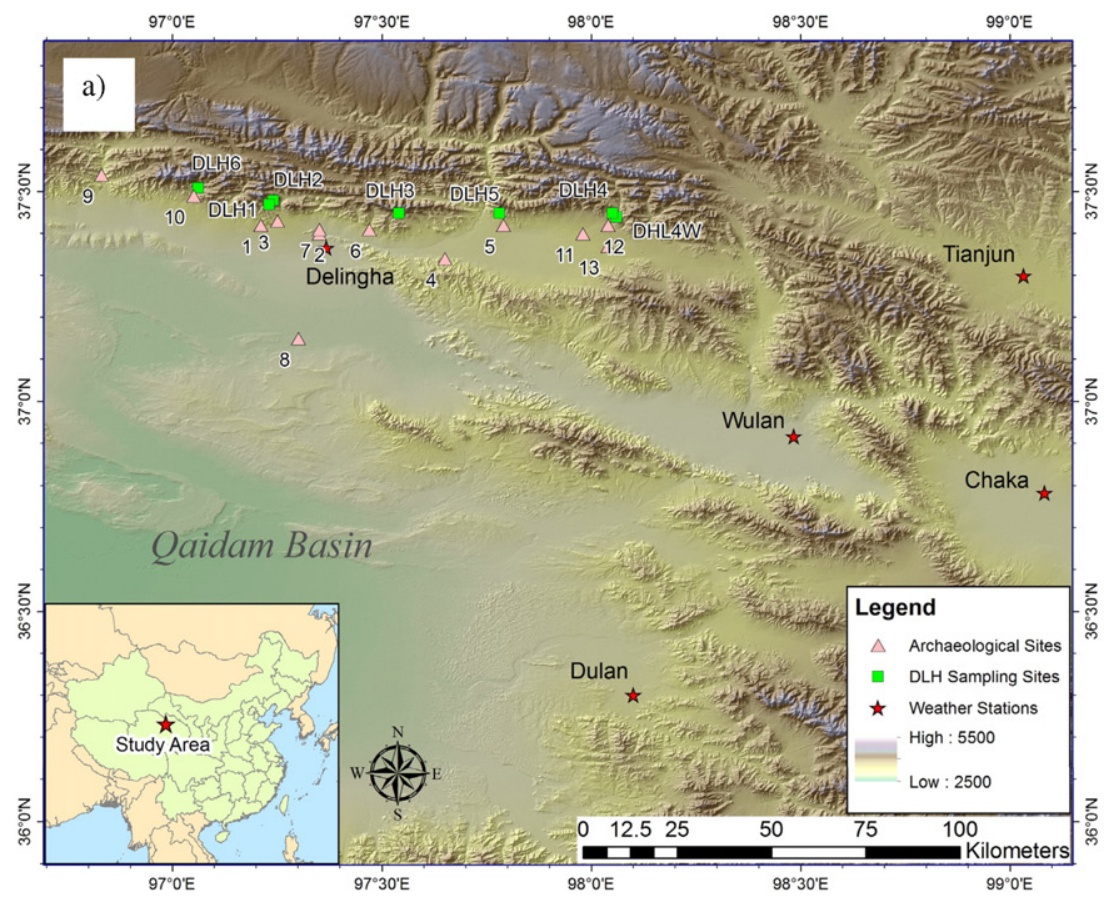

b)

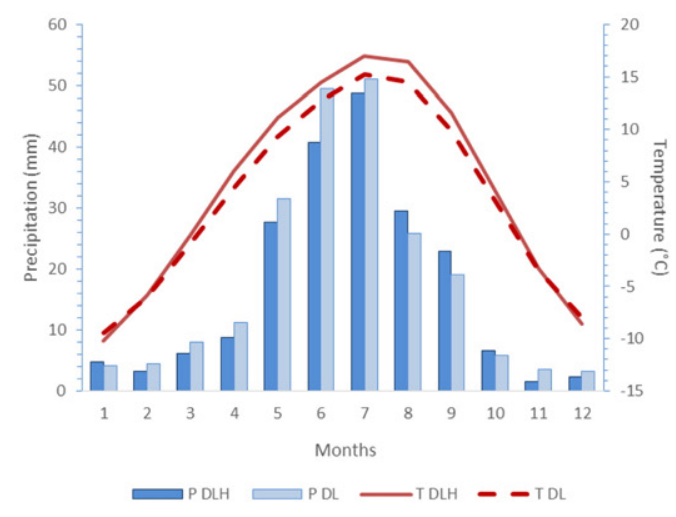

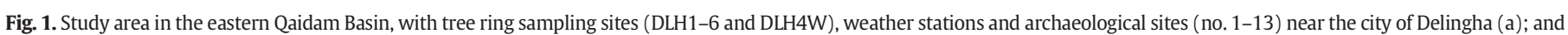

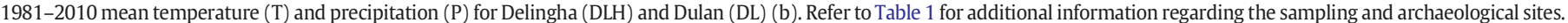


$266 \%$ of what was being recorded at the weather station. One complication was the direction of the precipitation gradient as the $42 \mathrm{~mm} / 100 \mathrm{~m}$ gradient was calculated based on a S-N profile, while the directions from Delingha to the sampling sites varied greatly (Fig. 1). Additionally, it was unclear whether this rate of precipitation increase with elevation would remain robust spatially. Therefore, caution must be exercised trying to use a single elevationprecipitation relationship for the entire region and the approach of spatial modeling with consideration of multiple terrain factors should render better results (Daly et al., 1994).

The goal of this study is to reconstruct the history of moisture condition fluctuation, especially moisture balance, based on the concept of water budget using a water balance model. The simulation results were calibrated by the ring-width data and therefore can be considered as biological drought indicators. We use a 3585-year ring width chronology based on Qilian juniper samples from both living and dead trees and archaeological wood (Shao et al., 2010) to reconstruct the history of moisture conditions in the alpine environment along the eastern margin of the Qaidam Basin, northeastern Tibetan Plateau. Of the 3585 years of tree ring record, 2848 years ( $843 \mathrm{BCE}-2005 \mathrm{CE}$ ) were considered reliable for climatic reconstructions according to the criterion of expressed population signal (EPS) > 0.85 (Shao et al., 2010; Wigley et al., 1984). This reconstructed series of biological drought history is further analyzed to reveal temporal variation patterns and relationships with potential forcing mechanisms, such as Asian monsoon intensity and solar activities.

\section{Data and methods}

\subsection{Study region and climatic data}

Fig. 1a shows the Delingha region of Qinghai Province in the eastern Qaidam Basin of the northeastern Tibetan Plateau. The elevation ranges from $2900 \mathrm{~m}$ a.s.l. in the foothills to over $4500 \mathrm{~m}$ on the mountain tops. The weather station used in this study is located in the city of Delingha (WMO ID 52737) with an elevation of $2982.4 \mathrm{~m}$ a.s.l. Monthly mean temperature and precipitation data for this station during 1955-2010 were obtained from the China Meteorological Administration's national monthly surface climatic dataset (SURF_CLI_CHN_MUL_MON, http:// cdc.cma.gov.cn/, last accessed on July 8, 2013). This region is dominated by a semi-arid continental climate with distinct seasonality (Fig. 1b). Mean annual temperature (1981-2010) was $4.40{ }^{\circ} \mathrm{C}$ at Delingha (DLH), while mean monthly air temperature varied from $-10.2{ }^{\circ} \mathrm{C}$ in January to $17.0^{\circ} \mathrm{C}$ in July. The long-term average annual total precipitation (1981-2010) was 203 mm, with most (> 80\%) falling during May through September. The 1981-2010 data for Dulan (elevation $3192.1 \mathrm{~m}$ a.s.l.) are also presented for comparison.

\subsection{Tree ring data}

Fig. 1a shows the tree-ring sampling sites and archaeological sites near Delingha as described in Shao et al. (2010). Qilian juniper is an endemic species in China (Wang, 1993), growing on the mountain slopes

Table 1

Information of the tree ring sampling sites used in this study. Refer to Shao et al. (2010) for more details.

\begin{tabular}{|c|c|c|c|c|c|c|c|}
\hline No. & Site code & $\begin{array}{l}\text { Latitude } \\
\mathrm{N}\end{array}$ & $\begin{array}{l}\text { Longitude } \\
\mathrm{E}\end{array}$ & $\begin{array}{l}\text { Elevation } \\
\mathrm{m}\end{array}$ & Site type & Specimen type & Sampled trees/cores \\
\hline & BGT & $37.42^{\circ}$ & $97.21^{\circ}$ & 3380 & Archaeological & Block & 8 \\
\hline 1 & BGX & $37.40^{\circ}$ & $97.35^{\circ}$ & 3060 & Archaeological & Block & 11 \\
\hline 2 & NHT & $37.43^{\circ}$ & $97.25^{\circ}$ & 3360 & Archaeological & Block & 4 \\
\hline 3 & & & & & & & \\
\hline 4 & XTT & $37.34^{\circ}$ & $97.65^{\circ}$ & 3190 & Archaeological & Block \& core & $46 / 77$ \\
\hline & MHG & $37.42^{\circ}$ & $97.79^{\circ}$ & 3290 & Archaeological & Core & $55 / 110$ \\
\hline 5 & AZG & $37.41^{\circ}$ & $97.47^{\circ}$ & 3245 & Archaeological & Block & 2 \\
\hline 6 & SNC & $37.41^{\circ}$ & $97.35^{\circ}$ & 3080 & Archaeological & Block & 11 \\
\hline 7 & BLE & $37.15^{\circ}$ & $97.30^{\circ}$ & 2877 & Archaeological & Block & 5 \\
\hline 8 & AQTG & $37.54^{\circ}$ & $96.83^{\circ}$ & 3336 & Archaeological & Block & 3 \\
\hline 9 & ZHG & $37.49^{\circ}$ & $97.05^{\circ}$ & 3544 & Archaeological & Block & 9 \\
\hline 10 & BRT & $37.40^{\circ}$ & $97.98^{\circ}$ & 3390 & Archaeological & Block & 8 \\
\hline 11 & GARG & $37.42^{\circ}$ & $98.04^{\circ}$ & 3556 & Archaeological & Block & 15 \\
\hline 12 & ALST & $37.37^{\circ}$ & $98.04^{\circ}$ & 3445 & Archaeological & Block & 5 \\
\hline 13 & DLH4W & $37.45^{\circ}$ & $98.05^{\circ}$ & 3720 & Living trees & Core & $23 / 46$ \\
\hline 14 & DLH1 & $37.48^{\circ}$ & $97.24^{\circ}$ & 3730 & Living trees & Core & $31 / 61$ \\
\hline 15 & DLH2 & $37.47^{\circ}$ & $97.23^{\circ}$ & 3780 & Living trees & Core & $34 / 73$ \\
\hline 16 & DLH3 & $37.45^{\circ}$ & $97.54^{\circ}$ & 3920 & Living trees & Core & $79 / 168$ \\
\hline 17 & DLH4 & $37.44^{\circ}$ & $98.06^{\circ}$ & 3800 & Living trees & Core & $67 / 144$ \\
\hline 18 & DLH5 & $37.45^{\circ}$ & $97.78^{\circ}$ & 3700 & Living trees & Core & $67 / 146$ \\
\hline $\begin{array}{l}19 \\
20\end{array}$ & DLH6 & $37.51^{\circ}$ & $97.06^{\circ}$ & 3780 & Living trees & Core & $29 / 67$ \\
\hline
\end{tabular}


between $3400 \mathrm{~m}$ and $4200 \mathrm{~m}$ a.s.l. in the study region. This elevation range matches the elevations of maximum precipitation in the northeastern Tibetan Plateau, between $3500 \mathrm{~m}$ and $4000 \mathrm{~m}$ a.s.l. according to Yeh and Gao (1979). Some of the tree ring samples (DLH1-6) were used in an earlier study by Yin et al. (2008), while the archaeological sites (no. 1-13) and DLH4W were described in Shao et al. (2010). While the living tree sites were found to be moisture sensitive, it was argued that the archaeological samples from the ancient tombs, dated to ca. $800 \mathrm{CE}$ or earlier, should also be moisture sensitive (Shao et al., 2010). Although this 3585-year chronology was compared to other millennium-long moisture-sensitive tree ring records in the region, it has not been used in any reconstruction of the past climate.

The sampling sites (DLH1-6 and DLH4W, Fig. 1a) have elevations ranging from $3700 \mathrm{~m}$ to $3920 \mathrm{~m}$ a.s.l. and are $19 \mathrm{~km}$ to $77 \mathrm{~km}$ from the weather station in Delingha. Both elevation differences and orographic precipitation make the microenvironments of the tree ring sampling sites cooler and wetter than the location of the weather station. Therefore, we first characterized the growth environment at the tree ring sampling sites, which was then used in water balance modeling to simulate the in situ moisture conditions. According to previous studies as discussed earlier, we assumed that the early growing-season moisture condition was the major limiting factor of tree growth in the study region and that the radial growth rates reflected temporal variations in the moisture conditions. This assumption formed the basis for us to use the tree ring data to verify the simulation results of the water balance model.

\subsection{Moisture balance of the alpine environment at the sampling sites}

Thornthwaite developed a climatic water balance model to simulate the components of hydrologic cycle using temperature and precipitation data (Thornthwaite and Mather, 1955). This model has been modified over time and proven effective in water resources investigations for temporal scales ranging from daily to multi-year periods (Black, 1996; Mather, 1978; Xu and Singh, 1998). We used a modified Thornthwaite monthly water balance model with an easy-to-use graphical user interface (McCabe and Markstrom, 2007). The McCabe \& Markstrom (thereafter as M\&M) model and its documentation can be downloaded from http://wwwbrr.cr.usgs.gov/projects/SW_MoWS/ Thornthwaite.html (last accessed on April 5, 2016). It requires the input data of monthly precipitation and mean temperature time-series and simulates potential and actual evapotranspiration, snow storage and melt, soil moisture, moisture deficit and surplus, and total runoff. In the M\&M model, the user needs to determine several model parameters, including soil-moisture-storage capacity or water hold capacity (WHC) that represents the maximum amount of moisture that can be stored in the soil column, direct runoff coefficient as the proportion of precipitation that directly turns into surface runoff without replenishing the soil storage, runoff factor or the proportion of the surplus in a given month to become runoff, threshold temperature that determines the form of precipitation as rain or snow, and the maximum melt rate as a percentage of the snow storage. McCabe and Markstrom (2007) stated that a WHC of $150 \mathrm{~mm}$ should suit most conditions. Yin et al. (2008) discovered that the correlation between the simulated soil moisture and tree growth in Delingha became stronger as WHC increases, mostly due to the fact that a small WHC value could lead to rapid depletion of soil moisture and keep it at zero in this semi-arid environment. Therefore, the WHC value was set to $100 \mathrm{~mm}$ in this study for all simulations, considering steep slopes and thin soil layers at the sampling sites. For all other parameters of the model, we kept them as the default values: $5 \%$ of precipitation as direct runoff, $0{ }^{\circ} \mathrm{C}$ as the threshold for solid or liquid precipitation, $50 \%$ of surplus of any given month to become runoff, and a maximum of $50 \%$ of snow melt during any given month (McCabe and Markstrom, 2007).

Without a dense weather station network, it is difficult to obtain an accurate precipitation field in regions with complex terrains. Various methods have been used to estimate orographic precipitation and to interpolate weather station data in regions with complex topography. For example, Daly et al. (1994) developed the Parameter-elevation Regressions on Independent Slopes Model (PRISM) to estimate spatial patterns of climatic variables based on point observations and digital topographic data. In the PRISM model, the climate-elevation relations, spatial scale of orographic effects, and various topographic variables such as slope gradient, slope aspect or orientation, coastal proximity, topographic position, and upwind barriers are considered. These topographic variables are then incorporated in a climate-elevation regression analysis using point station data, in which the stations entered the model for a specific grid location are of similar topographic characteristics and assigned different weights, so that the spatial patterns embedded in the point climatic data are reflected in the modeling process. The PRISM model has been used to generate spatial datasets of both long-term norms and time-series of precipitation and temperature in the U.S. with a spatial resolution up to 30 arc sec (Daly et al., 2008). For this study, we obtained the 1961-1990 long-term means of monthly precipitation data for China at the resolution of $0.05^{\circ} \times 0.05^{\circ}$ latitude and longitude (equivalent to approx. $5.5 \times 4.4 \mathrm{~km}$ at $37.5^{\circ} \mathrm{N}$ ) based on 2450 stations in China and neighboring countries (Daly et al., 2000). Using an independent monitoring dataset from the Chinese Ecosystem Research Network (CERN), Zhu et al. (2003) evaluated the PRISM dataset and found it to be accurate.

Another effort of constructing high-resolution spatial datasets of climatic variables produced the World Climate (WC) dataset by Hijmans et al. (2005). This dataset is based on weather station data from various sources during the period 1950-2000 and the thin-plate splines algorithm in the ANUSPLIN-SPLINA program (Hutchinson, 2004). A

\section{Table 2}

Correction factors for precipitation and temperature obtained from the World Climate (WC) and PRISM datasets: a) precipitation and b) temperature. The boldface columns are the respective correction factors for precipitation (WC and PRISM) and temperature (WC) data.

\begin{tabular}{|c|c|c|c|c|c|c|c|c|c|}
\hline \multirow{2}{*}{$\begin{array}{l}\text { a) } \\
\text { Month }\end{array}$} & \multicolumn{2}{|c|}{$\begin{array}{l}\text { PRCP } \\
\text { extracted } \\
\text { at-station } \\
(\mathrm{mm})\end{array}$} & \multicolumn{2}{|c|}{$\begin{array}{l}\text { Mean PRCP } \\
\text { extracted } \\
\text { at-site }(\mathrm{mm})\end{array}$} & \multicolumn{2}{|c|}{$\begin{array}{l}\text { Site-station } \\
\text { differences } \\
\text { (extracted } \\
\text { data) }\end{array}$} & \multicolumn{2}{|c|}{$\begin{array}{l}\text { Site-station } \\
\text { ratios } \\
\text { (extracted } \\
\text { data) }\end{array}$} & \multirow{2}{*}{$\begin{array}{l}\text { Observed } \\
1971-2000 \\
\text { means } \\
\text { PRCP }\end{array}$} \\
\hline & WC & PRSM & WC & PRSM & WC & PRSM & WC & PRSM & \\
\hline 1 & 3 & 2 & 3.0 & 2.3 & 0.0 & 0.3 & 1.0 & 1.1 & 4.0 \\
\hline 2 & 3 & 2 & 4.0 & 4.0 & 1.0 & 2.0 & 1.3 & 2.0 & 2.9 \\
\hline 3 & 3 & 3 & 4.9 & 5.3 & 1.9 & 2.3 & 1.6 & 1.8 & 4.6 \\
\hline 4 & 8 & 7 & 9.9 & 11.3 & 1.9 & 4.3 & 1.2 & 1.6 & 6.5 \\
\hline 5 & 21 & 22 & 27.3 & 39.3 & 6.3 & 17.3 & 1.3 & 1.8 & 21.2 \\
\hline 6 & 35 & 33 & 50.0 & 60.6 & 15.0 & 27.6 & 1.4 & 1.8 & 38.4 \\
\hline 7 & 33 & 34 & 51.0 & 67.6 & 18.0 & 33.6 & 1.5 & 2.0 & 40.9 \\
\hline 8 & 24 & 27 & 43.1 & 54.6 & 19.1 & 27.6 & 1.8 & 2.0 & 31.4 \\
\hline 9 & 15 & 15 & 24.0 & 39.0 & 9.0 & 24.0 & 1.6 & 2.6 & 17.6 \\
\hline 10 & 6 & 6 & 7.6 & 11.9 & 1.6 & 5.9 & 1.3 & 2.0 & 6.4 \\
\hline 11 & 2 & 1 & 2.0 & 1.9 & 0.0 & 0.9 & 1.0 & 1.9 & 1.2 \\
\hline 12 & 2 & 1 & 2.0 & 1.7 & 0.0 & 0.7 & 1.0 & 1.7 & 2.4 \\
\hline ANN & 155 & 153 & 228.7 & 299.3 & 73.7 & 146.3 & 1.5 & 2.0 & 177.4 \\
\hline b) & \multicolumn{2}{|c|}{$\begin{array}{l}\mathrm{T} \\
\text { extracted }\end{array}$} & \multicolumn{2}{|c|}{$\begin{array}{l}\text { Extracted } \\
\text { means }\end{array}$} & \multicolumn{3}{|c|}{$\begin{array}{l}\text { Site-station } \\
\text { difference }\end{array}$} & \multicolumn{2}{|c|}{$\begin{array}{l}\text { Observed 1971-2000 } \\
\text { means }\end{array}$} \\
\hline Month & \multicolumn{2}{|c|}{ At-station } & \multicolumn{2}{|l|}{ At-site } & \multicolumn{2}{|c|}{$\mathrm{T}$ mean } & & \multicolumn{2}{|c|}{$\mathrm{T}$ mean } \\
\hline 1 & \multicolumn{2}{|c|}{-11.3} & \multicolumn{2}{|l|}{-15.9} & \multicolumn{2}{|l|}{-4.6} & & \multicolumn{2}{|l|}{-10.9} \\
\hline 2 & \multicolumn{2}{|c|}{-7.6} & \multicolumn{2}{|l|}{-12.9} & \multicolumn{2}{|c|}{-5.4} & & \multicolumn{2}{|c|}{-6.6} \\
\hline 3 & \multicolumn{2}{|c|}{-0.8} & \multicolumn{2}{|l|}{-7.1} & \multicolumn{2}{|l|}{-6.4} & & \multicolumn{2}{|l|}{-0.5} \\
\hline 4 & \multicolumn{2}{|c|}{5.2} & \multicolumn{2}{|l|}{-1.3} & \multicolumn{2}{|l|}{-6.5} & & 5.6 & \\
\hline 5 & 10. & .3 & 3.7 & & -6.6 & & & 11.0 & \\
\hline 6 & 13. & .8 & 7.2 & & -6.5 & & & 14.2 & \\
\hline 7 & 16. & .5 & 10.1 & & -6.4 & & & 16.5 & \\
\hline 8 & 16. & 0 & 9.5 & & -6.4 & & & 16.2 & \\
\hline 9 & 10. & 8 & 4.7 & & -6.1 & & & 11.2 & \\
\hline 10 & 4. & .2 & -1.8 & & -5.9 & & & 3.9 & \\
\hline 11 & -4 & & -9.7 & & -5.7 & & & -3.8 & \\
\hline 12 & -9 & & -14.2 & & -4.7 & & & -9.2 & \\
\hline ANN & 3. & 6 & -2.3 & & -5.9 & & & 4.0 & \\
\hline
\end{tabular}



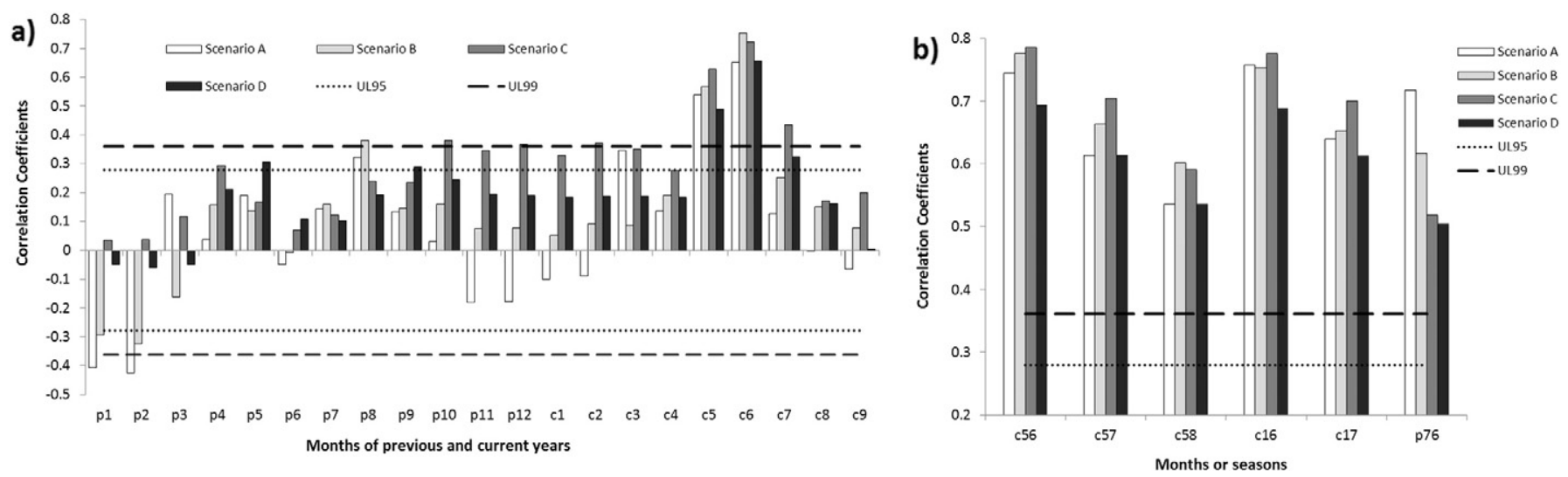

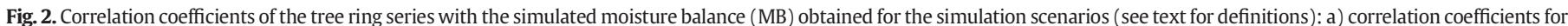

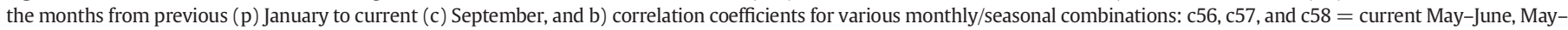

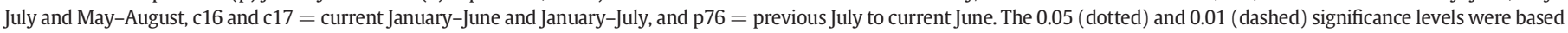
on the sample size of 49 (d.f. $=47$ ), while the actual sample sizes were 49-51.

continuous surface is fitted to the point data based on the second-order spline using latitude, longitude, and elevation as independent variables (Hijmans et al., 2005). For this study, we downloaded the long-term average data of both temperature and precipitation at the 30 arc sec resolution (equivalent to approx. $0.92 \times 0.74 \mathrm{~km}$ at $37.5^{\circ} \mathrm{N}$ ) (http://www. worldclim.org/, last accessed on 7/7/2012). In the Supplementary Material, a visual comparison between the two datasets for the study area (SM Fig. 1) and their usages in water balance modeling are presented (SM Figs. 2 and 3).

To obtain the estimates of precipitation time-series representative for the sampling sites, we extracted mean monthly precipitation data from both aforementioned spatial datasets (WC and PRISM) using the zonal statistics function of ArcGIS (ESRI, Redlands, CA) for the sampling sites and weather station. The ratios of the extracted values averaged for the sampling sites to the extracted station values (DLH) were used as the correction factors $\left(\mathrm{PCF}_{\mathrm{i}}\right)$ for the months January to December. Then a new precipitation time-series $\left(\mathrm{P}^{\prime}\right)$ was generated as $\mathrm{P}^{\prime}{ }_{\mathrm{ij}}=$ $\mathrm{P}_{\mathrm{ij}}$ * $\mathrm{PCF}_{\mathrm{j}}$, where $\mathrm{P}_{\mathrm{ij}}$ is the observed station precipitation value of a given month $\mathrm{j}$ of any year $\mathrm{i}$, and $\mathrm{PCF}_{\mathrm{j}}$ is the correction factor of the month j ( $\mathrm{j}=$ January to December, Table 2a). Similarly, we extracted temperature values for both the sampling sites and the weather station from the World Climate dataset for the months of January to December using ArcGIS. Instead of the ratios, we used the mean differences between the sites and the weather station as the correction factors $\left(\mathrm{TCF}_{\mathrm{j}}\right.$ ) (Table $2 \mathrm{~b}$ ), being added to the original weather station data to generate the new time-series of temperature for the sampling sites as $\mathrm{T}_{\mathrm{ij}}^{\prime}=\mathrm{T}_{\mathrm{ij}}+\mathrm{TCF}_{\mathrm{j}}$. The temperature estimates were corroborated by the average lapse rate of the lower troposphere as $-6.5{ }^{\circ} \mathrm{C} / 1000 \mathrm{~m}$ (Barry, 1992), which suggested that the temperatures (monthly and annual means) at the sampling sites should be $4.6-5.9{ }^{\circ} \mathrm{C}$ lower than the observed temperatures at the weather station as the elevation differences varied from $\sim 700 \mathrm{~m}$ to $\sim 900 \mathrm{~m}$ (Table $2 \mathrm{~b}$ ). All correction factors were calculated based on the means of 1971-2000 to match the original data represented by the WC and PRISM datasets.

\subsection{Moisture balance simulations and validation}

We set the following simulation experiments in order to determine the growth environment for the sampling sites:

Table 3

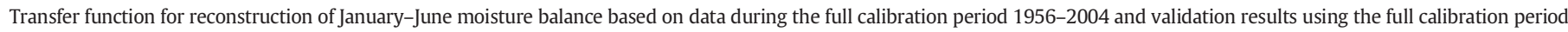

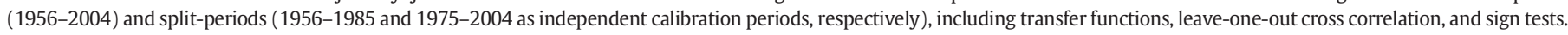
b1 and b2 are regression coefficients for $\operatorname{std}_{t}$ and $\operatorname{std}_{t}+1$.

\begin{tabular}{|c|c|c|c|c|c|c|c|c|c|}
\hline Full calibration & Coefficients & t-Value & p-Value & Std. err & $\mathrm{R}$ & $\mathrm{R}^{2}$-adj & $\mathrm{F}$ & p-Value & \\
\hline Constant & -147.690 & -11.390 & 0.000 & 16.772 & 0.822 & 0.661 & 47.820 & 0.000 & \\
\hline b1 & 69.242 & 9.550 & 0.000 & & & & & & \\
\hline b2 & 18.842 & 2.640 & 0.011 & & & & & & \\
\hline \multicolumn{10}{|l|}{ Independent validation } \\
\hline I: Calib. 1956-85, valid. 1986-04 & Coefficients & t-Value & p-Value & Std. err & $\mathrm{R}$ & $\mathrm{R}^{2}$-adj & $\mathrm{F}$ & p-Value & \\
\hline Constant & -126.120 & -7.628 & 0.000 & 14.333 & 0.749 & 0.528 & 17.234 & 0.000 & \\
\hline b1 & 54.725 & 5.841 & 0.000 & & & & & & \\
\hline b2 & 12.095 & 1.291 & 0.208 & & & & & & \\
\hline \multicolumn{10}{|l|}{ II: Calib. 1975-04, valid. 1956-74 } \\
\hline Constant & -129.210 & -7.030 & 0.000 & 18.220 & 0.792 & 0.600 & 22.730 & 0.000 & \\
\hline b1 & 64.843 & 6.690 & 0.000 & & & & & & \\
\hline b2 & 12.673 & 1.330 & 0.193 & & & & & & \\
\hline \multirow{2}{*}{ Sign test results } & \multicolumn{3}{|l|}{ Signs } & \multicolumn{6}{|c|}{ Signs 1st diff } \\
\hline & Calculated & [ST] 95\% & [ST] 99\% & Calculated & [ST] 95\% & [ST] 99\% & $\mathrm{RE}$ & $\mathrm{CE}$ & $\mathrm{r}$ \\
\hline Full calibration period 1956-04 & $38^{* *}$ & 32 & 34 & $38^{* *}$ & 32 & 34 & 0.621 & / & 0.789 \\
\hline I: Calib. 1956-85, valid. 1986-04 & $19^{* *}$ & 15 & 16 & $18^{* *}$ & 14 & 15 & 0.682 & 0.571 & 0.858 \\
\hline II: Calib. 1975-04, valid. 1956-74 & $15^{*}$ & 15 & 16 & $14^{*}$ & 14 & 15 & 0.726 & 0.198 & 0.863 \\
\hline
\end{tabular}

\footnotetext{
* 0.05 significance level.
}

* 0.01 significance level. 

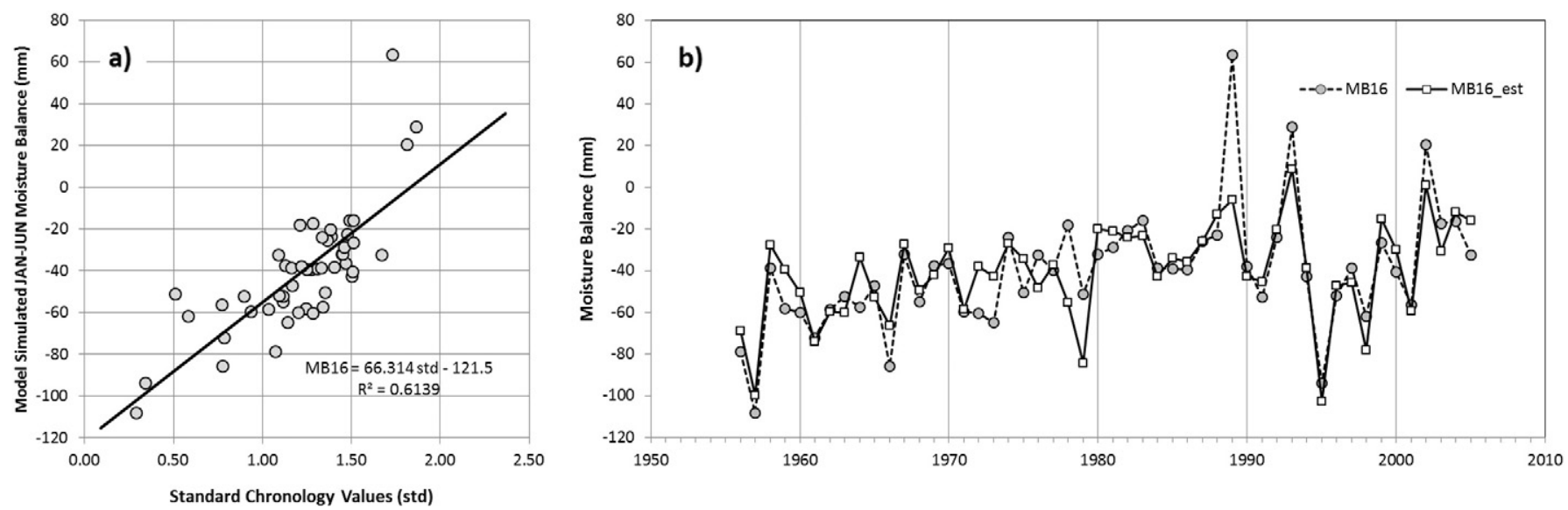

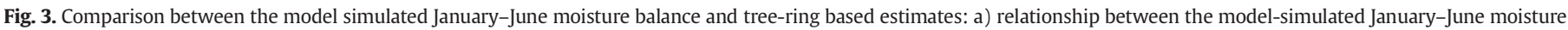

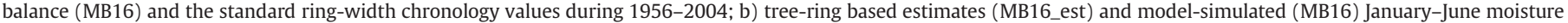
balance during the calibration period 1956-2004. It should be noted that the simple linear relationship in a) is different from the final transfer function used in reconstruction.

1. At-station simulation (Scenario A): in this scenario, the original weather station data of temperature and precipitation were used and the results were considered as the control for comparison.

2. At-site simulations: three scenarios were considered in simulations for the in situ moisture conditions:

a. Scenario B: site temperatures were estimated using the WC dataset, but the weather station precipitation data were used (no orographic effect on precipitation);

b. Scenario C: both temperature and precipitation of the WC dataset were used in simulation; and

c. Scenario D: WC temperature and PRISM precipitation data were used in simulation.

Since none of the tree ring samples used in this study was from the upper tree-line sites, we assumed that the simulated moisture conditions can be validated by the moisture-sensitive tree ring data (Shao et al., 2010). In other words, we can characterize the growth environments of the sampling sites when the simulated moisture conditions best correlate with the tree growth or ring width series. Of the outputs from the M\&M water balance model, we considered the following variables in characterizing the growth environment of the sampling sites (Mather, 1978; McCabe and Markstrom, 2007):
1) P-PET: the difference between precipitation and PET, as an indicator of instantaneous water use demand of the current month;

2) AET: actual evapotranspiration that is fulfilled by precipitation of the month, plus any extraction from soil moisture storage;

3) SM: soil moisture as simulated soil water content after moisture depletion due to actual evapotranspiration;

4) DEF: moisture deficit as PET-AET, used as a measure of vegetation water use shortage; and

5) SURP: moisture surplus that only occurs when P > PET and when SM has reached WHC, which will turn into runoff.

Among these variables, P-PET and SM reflect the instantaneous moisture conditions of the current month, while AET, DEF and SURP reflect the cumulative effects of moisture conditions in previous months as well. By combining DEF and SURP, we define the variable of moisture balance of a given time period as:

$\mathrm{MB}=(-\mathrm{DEF})+\mathrm{SURP}$

with negative values representing vegetation water use shortage, positive values representing presence of excessive water, and zero's for the conditions when water supply (precipitation and soil moisture usage) meeting vegetation water use demand with neither excess nor deficit.

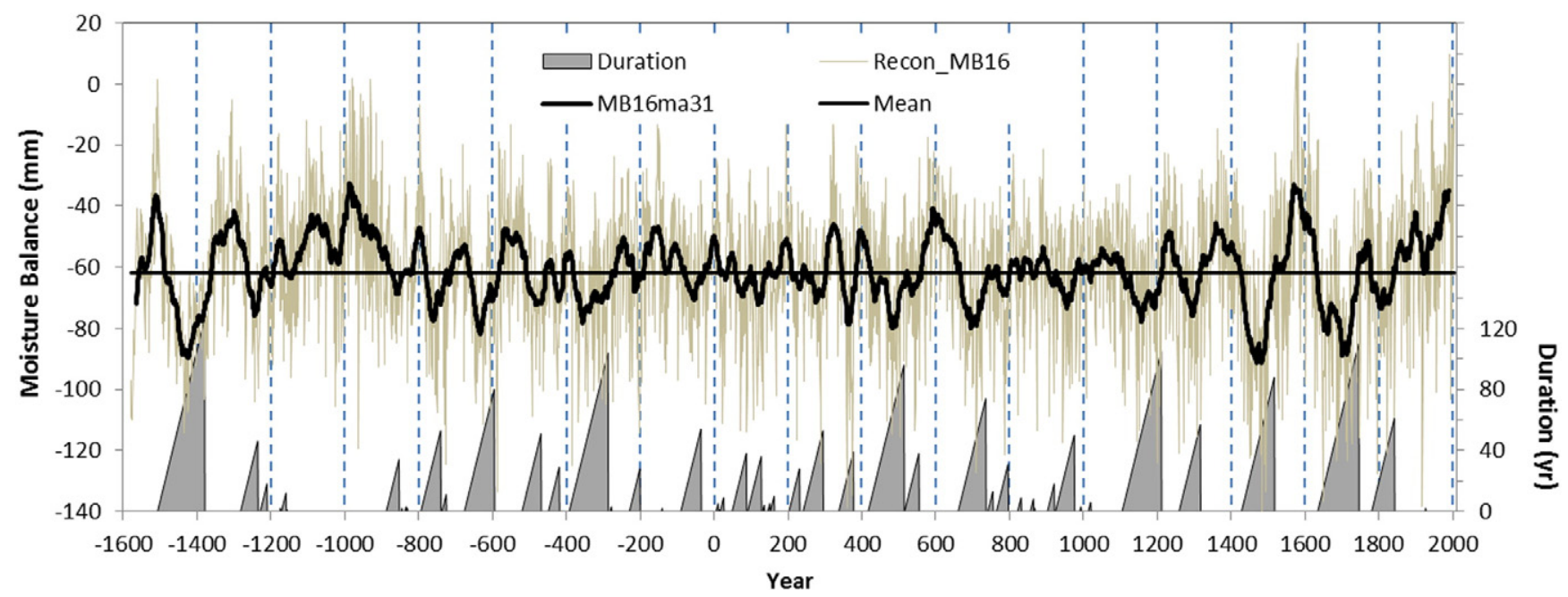

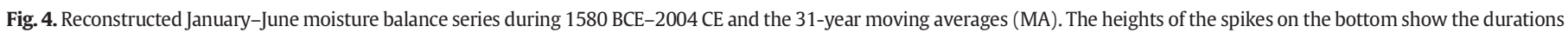
(years) of the decadal-scale dry periods with 31-year MA $<$ long-term mean of $-61.9 \mathrm{~mm}$. 
The moisture balance (MB) series was reconstructed using the 3585year ring width chronology by establishing the transfer function for the calibration period with instrumental data. Validation of the calibration equation was performed using the independent method (Fritts, 1976) and leave-one-out procedure (Michaelsen, 1987). To determine the relationships between the reconstructed MB series and other proxies of climate and forcing mechanisms, Pearson's correlation analysis was employed. Due to moderate to strong autocorrelations existed in these time-series data, whenever possible we calculated the effective sample size for long time-series $(\mathrm{N}>30)$ using the following equation:

$\mathrm{N}_{\text {Effective }}=\mathrm{N}\left(1-\mathrm{r}_{1} * \mathrm{r}_{2}\right) /\left(1+\mathrm{r}_{1} * \mathrm{r}_{2}\right)$,

where $\mathrm{N}=$ original sample size or series length, and $\mathrm{r}_{1}$ and $\mathrm{r}_{2}=\operatorname{lag} 1$ autocorrelation in the two series involved (Bretherton et al., 1999). The effective sample size was then used in the re-assessment of the statistical significance of the correlation coefficient.

\section{Results and discussions}

3.1. Relationships between the tree ring data and simulated moisture balance

When the simulated moisture balance $(\mathrm{MB})$ series were correlated with the ring width series (Fig. 2), it was found that various levels of improvements were achieved in Scenarios B and $C$ as compared to the atstation condition (Scenario A), while the simulations using the PRISM data (Scenario D) produced somewhat mediocre results. MB generated from Scenario C (WB) had a continuous run of statistically significant correlations from previous October to current July (Fig. 2a), a performance matched by none other. The months with the highest correlations were May and June for all simulation experiments, confirming our assumption that the early growing season moisture condition acted as the limiting factor of tree growth. When multiple months/seasons were considered (Fig. 2b), the May-June and January-June
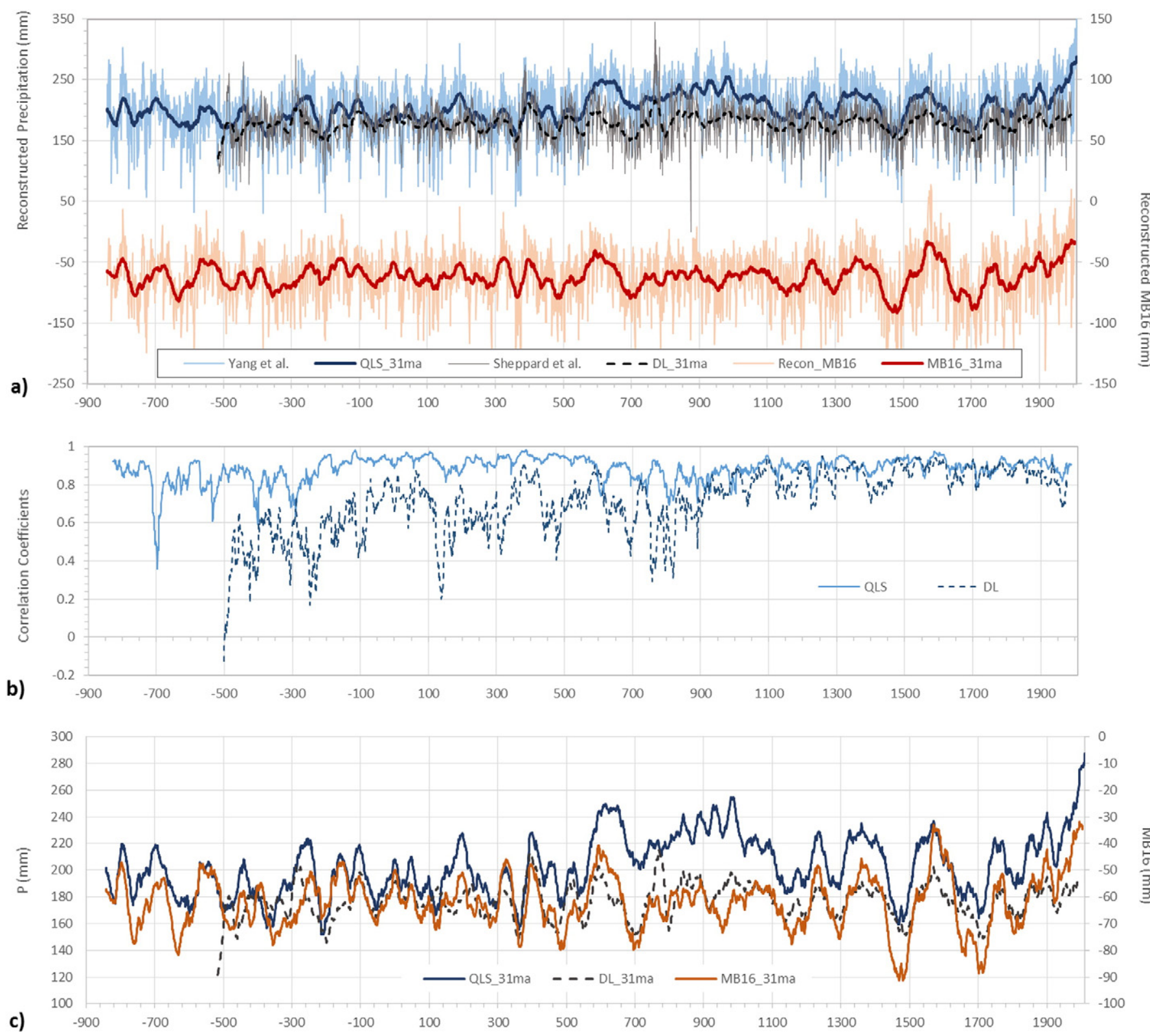

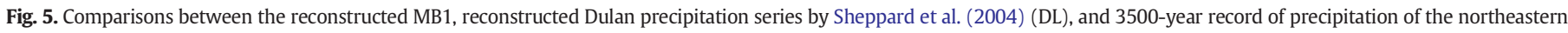

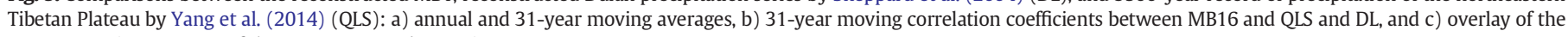
31-year moving averages of the MB16, QLS, and DL series. 
moisture balance (MB56 and MB16) performed almost equally well, and in both cases Scenario C (WC) produced the strongest correlations.

\subsection{Reconstruction of January-June moisture balance and validation}

Based on the comparison of simulation results using the WC and PRISM data in characterizing the growth environment of the sampling sites (SM Figs. 2 and 3) and the correlations between the simulated moisture balance and tree ring data (Fig. 2), we decided to reconstruct the January-June moisture balance (MB16) because of its cumulative effects on tree growth. The weather station data were corrected by the WC dataset to represent the average growth environment for the sampling sites. While winter and early-spring moisture conditions mostly influence tree growth through snow melt water that enhances soil moisture in the early growing season (Fritts, 1976), the May-June moisture balance must have contributed the majority of the interannual variability of MB16 (Fig. 2). Stepwise regression revealed that both the tree ring data of the current year $(t)$ and the year after $(t+1)$ entered the model at the 0.05 significance level, suggesting that long-lasting effects of the moisture conditions during the current January-June continued to affect tree growth in the following year. The final regression model or the transfer function is MB16 $_{t}=-147.690+69.242 * \operatorname{std}_{t}+18.842 * \mathrm{std}_{\mathrm{t}+1}$, which explains $>66 \%$ of the variance in MB16 (adjusted $\mathrm{R}^{2}=0.661$, Table 3).

In validation of the transfer function using the independent method (Fritts, 1976), we divided the full calibration period 1956-2004 into two sections in two steps. In each step, we used 30 years of data for calibration and the remaining years for validation, one using the earlier 30 years as the calibration period and the other one using the last 30 years as the calibration period: a) 1956-1985 for calibration and 1986-2004 for validation, and b) 1975-2004 for calibration and 19561974 for validation. Although the two split calibration periods overlapped by 11 years, the two validation periods were fully independent. The results presented in Table 3 indicate that the transfer function was robust during the full calibration period with strong statistical significance. The correlation between the simulated MB16 and the estimated values in the leave-one-out validation (Michaelsen, 1987) was 0.789 , suggesting good model performance during the full calibration period (Table 3). The transfer function also passed the sign test (Fritts, 1976) at the 0.01 significance level for the full calibration period and at the 0.05 significance level for the split validation periods (Table 3 ), which means that the model was capable of making predictions with correct directions for both original data and 1st-diference data. Additionally, both reduction of error (RE) and coefficient of efficiency (CE) values were positive, which served as indicators of model performance in comparisons between the model-predicted values and the observed values for both the calibration and validation periods (Fritts, 1976). Fig. 3 presents first the relationship between the model-simulated January-June moisture balance (MB16) and the tree-ring data (standard chronology values) (Fig. 3a) and then the model-simulated and tree-ring based reconstruction of the MB16 series during the full calibration period 1956 2004 (Fig. 3b). It can be seen that a simple linear relationship would have explained $>61 \%$ of the variance in MB16, but the inclusion of the next year's tree ring data further improved the model performance $\left(\mathrm{R}^{2}\right.$-adj $\left.=0.661\right)$. The reconstructed series captured the characteristics of both the short-term fluctuation patterns and long-term trends (Fig. 3b).

Fig. 4 shows the reconstructed series of MB16 from 1580 BCE to 2004 $\mathrm{CE}$ and the 31-year moving averages (MA). According to the criterion of expressed population signals (EPS) $>0.85$ (Shao et al., 2010; Wigley et al., 1984), the data after 843 BCE (total of 2847 years) were considered reliable and further analyzed in the following. Table 5 contains descriptive statistics and results of frequency analysis of the reconstructed series. For the period $843 \mathrm{BCE}-2004 \mathrm{CE}$, the mean value was $-61.9 \mathrm{~mm}$, suggesting that the Qilian juniper's grow environment was under persistent water-use stress during the first half of the calendar year, especially in the early growing season, which explains the overall narrow ring widths and high percentages of missing rings associated with the tree ring data in this region (Shao et al., 2005; Yin et al., 2008), and further validates that moisture condition is the main control factor of tree growth at the sampling sites.

\subsection{Comparisons with two reconstructed precipitation series}

In Shao et al. (2010), the 3585-year chronology was compared with a 2326-year moisture-sensitive tree ring chronology for the Dulan area by Zhang et al. (2003). We compared the reconstructed MB16 series (1580 BCE to 2004 CE) with the 2509-year reconstructed annual precipitation series (previous July-current June) of Sheppard et al. (2004) from Dulan (hereafter as DL reconstruction), located at approximately $120 \mathrm{~km}$ to the southeast of Delingha (Fig. 1a). The reconstructed precipitation series for the period 516 BCE-1993 CE (after 0 CE was reassigned as $1 \mathrm{BCE}$ ) was based on both living and archaeological samples (Sheppard et al., 2004). Since precipitation has much greater interannual variability than temperature, its contribution to moisture balance is also expected to be larger than temperature's. Therefore, our reconstructed MB16 series should have strong similarities with the DL reconstruction. Fig. 5a indicates that the two series indeed have strong similarities at the interannual and interdecadal time scales. After a missing year was inserted in $875 \mathrm{CE}$ (as a blank) to the DL reconstruction (Shao et al., 2007; Shao et al., 2009), the correlation between the two series became 0.671 for the common period. A running correlation analysis using a 31-year moving window revealed that high correlations between the two series existed from the most recent period back to approximately $900 \mathrm{CE}$ (Fig. 5b). The differences between the two series came from the different climatic variables reconstructed, even though both series represent moisture conditions, as well as spatial variations in precipitation due to local atmospheric circulation and orographic effects between the two areas. The varying robustness of the relationship, as indicated by periods of high and low correlations (Fig. 5b), may also have resulted from low sample depths in the earlier periods and issues associated with dating the archaeological samples (Sheppard et al., 2004; Shao et al., 2007; Shao et al., 2009). In a recent study, Yang et al. (2014) constructed a 3500-year precipitation record for the northeastern Tibetan Plateau by combining Qilian juniper samples from living and dead trees from the Qilian Mountains, Delingha and Dulan with archaeological samples in Delingha and Dulan (hereafter as QLS reconstruction). We obtained the unfiltered reconstructed precipitation series from the NOAA Paleoclimate database (https://www.ncdc.noaa. gov/cdo/f?p=519:1:::::P1_study_id:16034, latest access on June 15, 2015). A comparison between the reconstructed MB16 and the QLS

Table 4

Descriptive statistics of the 2847-year reconstructed January-June moisture balance and magnitudes of drought events of different return intervals.

\begin{tabular}{ll}
\hline Descriptive statistics & Values \\
\hline Series length & 2847 years \\
& $(843$ BCE-2004 CE) \\
Mean (mm) & -61.9 \\
Median (mm) & -60.6 \\
Skewness & -0.3207 \\
Kurtosis & 0.4185 \\
Minimum (mm) & -140.1 \\
Maximum (mm) & 13.4 \\
& \\
Frequency of occurrence (return interval) & Magnitude (mm) \\
\hline $0.1 \%(1000$-year) & -138.6 \\
$0.2 \%$ (500-year) & -134.1 \\
$0.5 \%(200$-year) & -124.4 \\
$1 \%(100$-year) & -117.3 \\
$2 \%$ (50-year) & -110.2 \\
$5 \%(20$-year) & -99.1 \\
$10 \%$ (10-year) & -89.7 \\
\hline
\end{tabular}




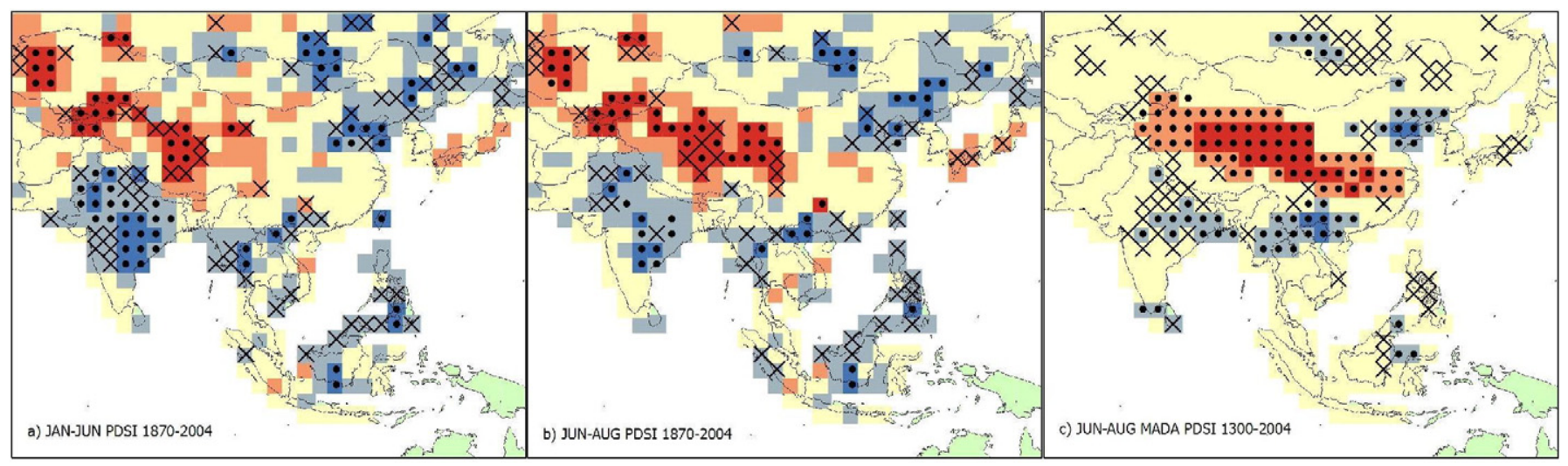

\section{Correlation Coefficients}

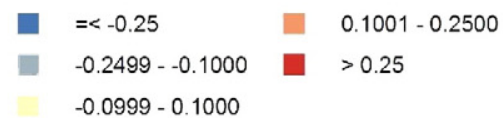

\section{Significance}

$\times \quad 0.05$

- 0.01

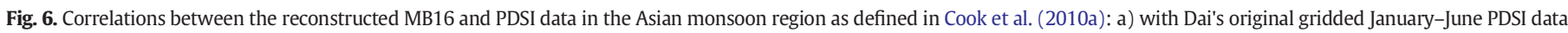

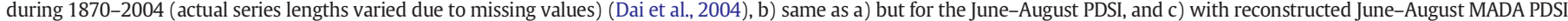
data during 1300-2004 (Cook et al., 2010a). Areas with "x" represent statistical significance of 0.05, while those with "•" represent statistical significance of 0.01.

reconstruction revealed similar patterns of interannual variations for the period 843 BCE-2004 CE (Fig. 5a), with an overall correlation of 0.833. Running correlations with the 31-year moving window revealed periods with low correlations, mostly prior to $200 \mathrm{BCE}$ (Fig. 5b). Also, there was a sudden jump in the QLS series during 500-600 CE, visible from the 31-year moving average series (Fig. 5c), which was close to the junction point between the living-tree samples and archaeological samples and may have caused the divergence between the two series for the next 1000 years. Finally, the QLS reconstruction showed a more prominent increasing trend since the early 1900s than the other two reconstructions (Fig. 5c). Even with these discrepancies, the above comparisons suggest that our reconstructed January-June moisture balance series has strong regional representativeness, and should serve as an effective proxy of biological drought conditions, especially in the high-frequency domain to represent the interannual variability.

\subsection{Frequencies and spatial structures of extreme drought events}

One of the advantages of such long records is to discover and assess the historical significance of extreme events. We calculated the magnitudes of drought events with various return intervals up to 1000 years using the 2847-year series (Table 4). The most recent severe drought occurred in 1995 with a magnitude of $-103.5 \mathrm{~mm}$, which had a return interval of approximately 27 years; while the most recent extreme drought occurred in 1918 with a magnitude of $-138.6 \mathrm{~mm}$, which was ranked as the third most severe event since $843 \mathrm{BCE}$ with a return interval of approximately 950 years. This return interval would not have been possible to derive directly from data without any probabilityfunction fitting if the series length had been shorter than 1000 years. The longest dry-period duration since 843 BCE (as 31-year moving averages of MB16 consistently below the mean) was found during
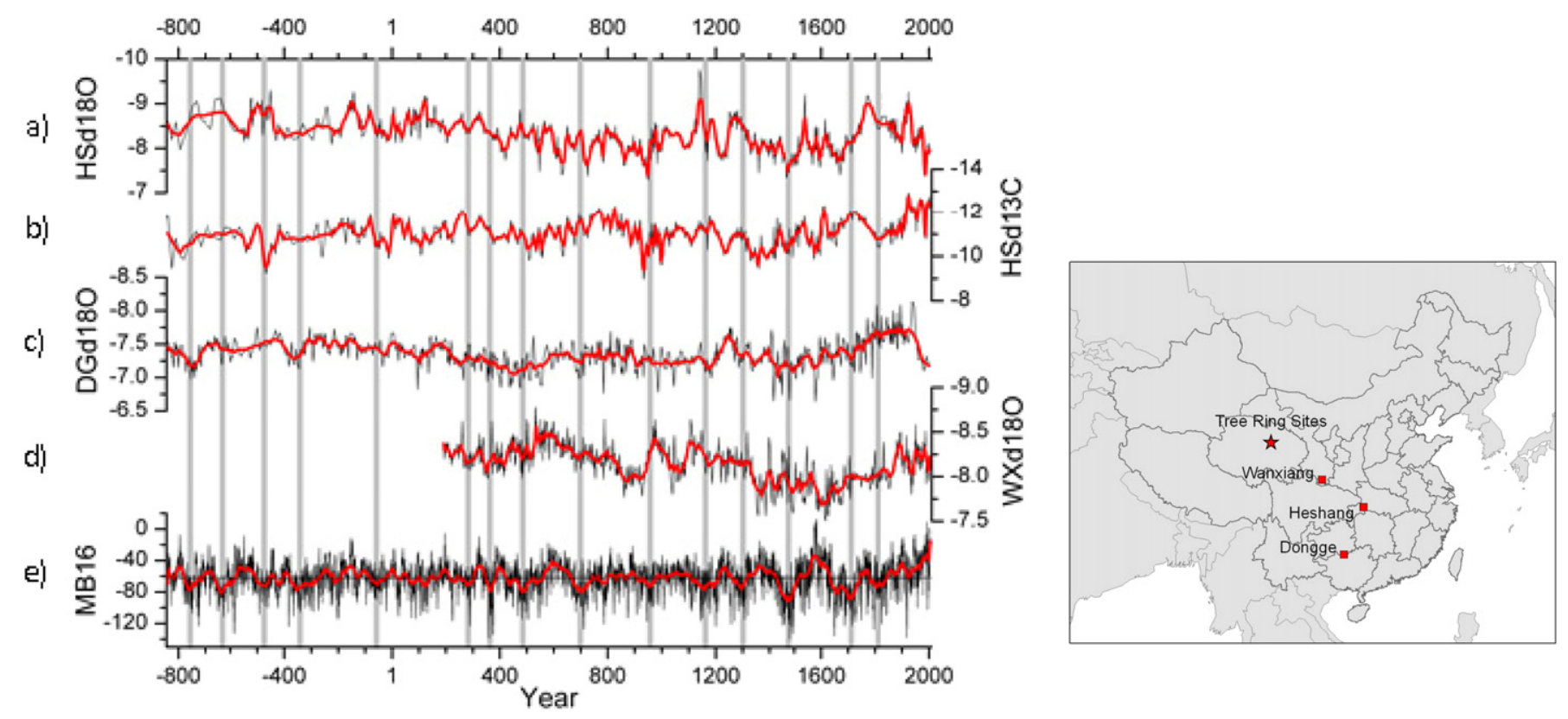

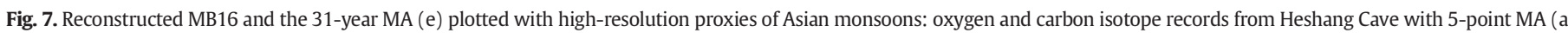
and b), Dongge Cave with 9-point MA (c), and Wanxiang Cave with 9-point MA (d). Vertical lines represent major multi-decadal drought events since 843 BCE. 
Table 5

Correlation coefficients between the reconstructed MB16 (and its moving averages: 11year and 31-year) and stable isotope series from Heshang, Wanxiang, and Dongge Caves. All initially statistically significant correlations were retested for statistical significance based on the effective samples sizes (Effective $\mathrm{N}$ ) corrected for autocorrelations in both series (Bretherton et al., 1999).

\begin{tabular}{|c|c|c|c|c|c|}
\hline \multirow{2}{*}{\multicolumn{2}{|c|}{$\begin{array}{l}\text { Reconstructed moisture } \\
\text { balance }\end{array}$}} & \multicolumn{2}{|c|}{ Heshang Cave } & \multirow{2}{*}{$\frac{\text { Wanxiang }}{\mathrm{d} 180}$} & \multirow{2}{*}{$\frac{\text { Dongge }}{\mathrm{d} 180}$} \\
\hline & & d180 & $\mathrm{d} 13 \mathrm{C}$ & & \\
\hline \multirow[t]{4}{*}{ Recon_MB16 } & $r$ & 0.017 & -0.062 & -0.054 & $-0.082^{*}$ \\
\hline & Sig. (2-tailed) & 0.609 & 0.063 & 0.149 & 0.030 \\
\hline & $\mathrm{N}$ & 902 & 902 & 705 & 711 \\
\hline & $\begin{array}{l}\text { Effective N } \\
\text { Sig. } \\
\text { (corrected) }\end{array}$ & 599 & 591 & 406 & $\begin{array}{l}521 \\
0.033\end{array}$ \\
\hline \multirow[t]{5}{*}{ MB16ma11 } & $\mathrm{r}$ & 0.031 & $-0.133^{* *}$ & -0.044 & $-0.123^{* *}$ \\
\hline & Sig. (2-tailed) & 0.356 & 0.000 & 0.247 & 0.001 \\
\hline & $\mathrm{N}$ & 902 & 902 & 705 & 711 \\
\hline & Effective N & 137 & 122 & 171 & 244 \\
\hline & $\begin{array}{l}\text { Sig. } \\
\text { (corrected) }\end{array}$ & & 0.144 & & 0.055 \\
\hline \multirow[t]{5}{*}{ MB16ma31 } & $\mathrm{r}$ & 0.015 & $-0.207^{* *}$ & -0.057 & $-0.159^{* *}$ \\
\hline & Sig. (2-tailed) & 0.662 & 0.000 & 0.133 & 0.000 \\
\hline & $\mathrm{N}$ & 902 & 902 & 705 & 711 \\
\hline & Effective N & 100 & 86 & 151 & 203 \\
\hline & $\begin{array}{l}\text { Sig. } \\
\text { (corrected) }\end{array}$ & & 0.056 & & 0.023 \\
\hline \multicolumn{2}{|l|}{ Data periods } & \multicolumn{2}{|c|}{$\begin{array}{l}840 \text { BCE-2002 } \\
\text { CE }\end{array}$} & $192-2003 \mathrm{CE}$ & $\begin{array}{l}841 \text { BCE-2000 } \\
\text { CE }\end{array}$ \\
\hline \multicolumn{2}{|c|}{$\begin{array}{l}\text { Average (min-max) } \\
\text { sampling intervals }\end{array}$} & \multicolumn{2}{|c|}{$3.2(1-27)$ years } & $\begin{array}{l}2.6(1-5) \\
\text { years }\end{array}$ & $4(1-11)$ years \\
\hline
\end{tabular}

* 0.05 significance level

* 0.01 significance level.

1634-1743 CE, lasting 110 years (Fig. 4). Equally impressive were the dry-periods during 380-277 BCE (104 years), 425-520 CE (96 years), 1108-1212 CE (105 years), and 1429-1516 CE (88 years) (Fig. 4).

To examine the relationship between local drought events and large-scale drought occurrence, we performed correlation analysis between the reconstructed MB16 and the gridded data (Dai et al., 2004) of the Palmer's Drought Severity Index (PDSI, Palmer, 1965) during 1870-2005 for the same grid points covered by the Monsoon Asia Drought Atlas (Cook et al., 2010a). It was found that the January-June PDSI data were most strongly correlated to our reconstructed series at those grids in and surrounding our study region with maximum correlation coefficients higher than 0.5 (Fig. 6a). Similar results were found in the correlation between the reconstructed MB16 and the gridded JuneAugust PDSI data (Fig. 6b). This suggested that the impacts of the January-June moisture condition could be well extended into the summer due to cumulative effects. Additionally, we performed correlation analysis between the reconstructed MB16 series and the June-August PDSI of the Monsoon Asia Drought Atlas (MADA) dataset during 13002005 (Cook et al., 2010a) and again found similar patterns (Fig. 6c). In fact, the highest correlation with the MADA data was 0.646, higher than the maximum correlations with the Dai's original PDSI data $(\mathrm{r}=$ 0.534 and $r=0.568$ for January-June and June-August PDSI, respectively). This was because the construction of the MADA dataset used tree ring data from a number of sites in the northeastern Tibetan Plateau, including the tree ring data of Sheppard et al. (2004) from Dulan. The spatial extent of the area with significant positive correlations surrounding our sites covered a region running NW-SE for approximately $20^{\circ}$ longitudes by $10^{\circ}$ latitudes, suggesting good spatial representativeness of our reconstruction. It was also interesting to note in Fig. 6 the apparent teleconnection or oscillation patterns found between the area surrounding our study sites with + r's and other areas in the Asian monsoon region, such as North-Northeast China, South China, and India with -r's. This spatial pattern is similar to the DEOF1 pattern identified in Cook et al. (2010a) and probably indicates that moisture conditions of the study region responded to various components of the Asian monsoon system in different ways.

Long records of proxies of Asian monsoon intensity have been developed based on oxygen and carbon isotopes in stalagmites from the Dongge Cave in southwestern China (Wang et al., 2005), Wanxiang Cave (Zhang et al., 2008) in central-western China, and Heshang Cave in central China (Hu et al., 2008) (Fig. 7). Since these series had varying sampling intervals, we retrieved the corresponding annual and movingaverages centered at the sampling year of the stalagmite series. It was found that the reconstructed MB16 was significantly correlated with Dongge Cave's oxygen isotope series, but not correlated with the Wanxiang Cave $\delta 180$ series (Table 5 ), which was located closest to the our study region (Fig. 7). Also, it was significantly correlated with the Heshang Cave's carbon isotope series for the original sample size, but not quite so after the correction for autocorrelations ( $p$-value $=0.056$ ). All the statistically significant correlations were negative (Table 5), indicating that the interannual variation in moisture condition of the early growing season in the study region is probably more related to the westerly circulation rather than the Asian summer monsoon circulation. As stated earlier, May-June precipitation contributed significantly to the MB16 interannual variability. The main mechanism to produce rainfall in the study region at this time should be frontal activities associated with the cold-season westerly circulation, since the Asian monsoon's rainy belts are still located south of the Yangtze River in May (Ding and Wang, 2008). Additionally, strong cold-season westerly circulation may produce above-normal snow depth over the Tibetan Plateau, including the study region, and snow melt water contributes to the early growing-season moisture balance and enhances tree growth. Previous studies have found that excessive snow over the Tibetan Plateau or the Eurasian continent may reduce the land-sea thermal
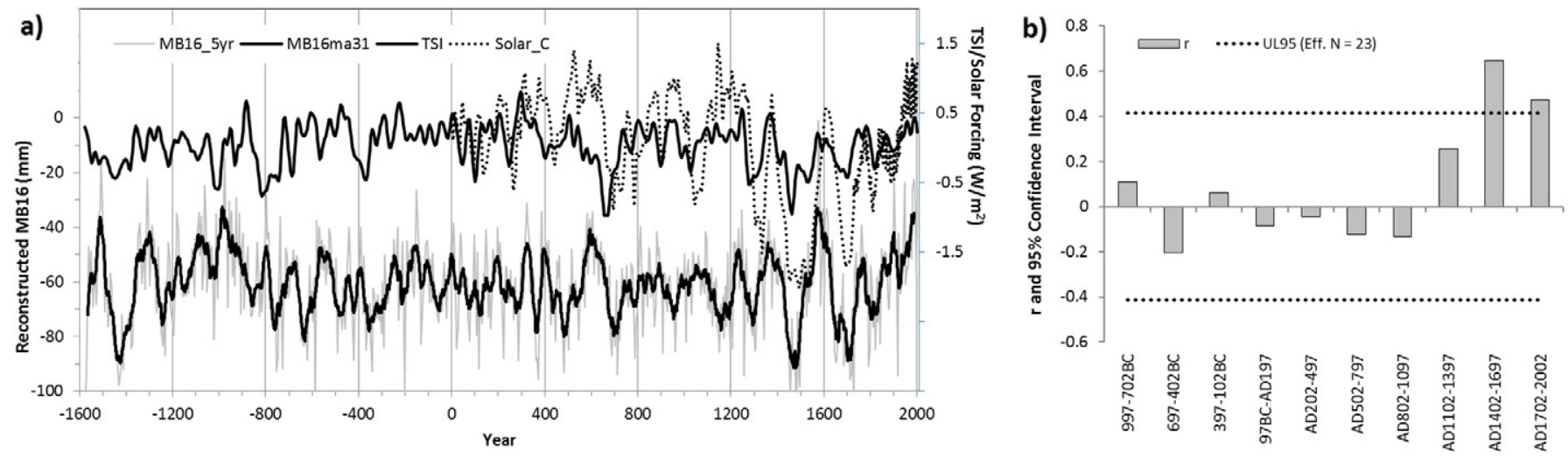

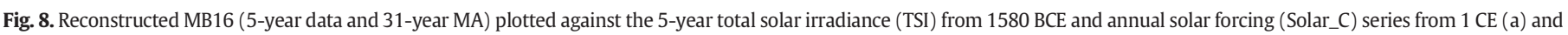
correlations between MB16-5 year (1st order autocorrelation $\left.r_{a}=0.454\right)$ and TSI (1st order autocorrelation $\left.r_{a}=0.959\right)$ for individual 300-year time blocks $\left(\mathrm{N}=60\right.$, $\mathrm{N}_{\mathrm{Effective}}=23$ ). 
Table 6

Correlations between MB16 and solar activity (TSI with the 5-year MB16 series during 842 BCE-2002 CE and annual solar forcing with annual MB16 series during 1-2001 CE, respectively), including the significance levels for both the original series lengths $(\mathrm{N})$ and the effective sample sizes corrected for the series autocorrelations (Effective N's).

\begin{tabular}{llll}
\hline & & TSI-5 years & Solar_C \\
\hline MB16 (5-year and annual) & r & $\mathbf{0 . 1 1 9}$ & $\mathbf{0 . 1 8 9}$ \\
& Sig. (2-tailed) & 0.004 & 0.000 \\
& N & 570 & 2001 \\
& Effective N & 224 & 597 \\
& Sig. (Effective N) & 0.076 & 0.000 \\
\hline
\end{tabular}

Bold values are significant at the 0.01 level for the original sample sizes.

contrast in the following monsoon season and affect the Asian monsoon intensities (Hahn and Shukla, 1976; Li and Yanai, 1996; Liu and Yanai, 2002; Wu and Qian, 2003), apparently explaining the negative correlations between the reconstructed MB16 and the proxies of East Asian monsoon. However, these relationships are complex and may be temporarily and spatially variable (Zhang et al., 2004; Zhao et al., 2007) and, therefore, require further investigation.

\subsection{Relationships between moisture conditions and solar activity}

Previous studies have explored the relationships between tree growth in the study region and solar activities. Huang and Shao (2005) found positive correlations between solar activity and a treering based precipitation reconstruction in Delingha for the past 400 years at different temporal scales, ranging from 33-year to 100year cyclic patterns. Raspopov et al. (2008) discovered the 200 year cycles in millennium-long tree ring data from Delingha and other sites in the mountains of Central Asia, but the cycles in the tree ring data had variable phase shifts with the 210-year de Vries solar cycle. More recently, based on a reconstructed millennium-long precipitation record in the Qilian Mountains to the north of our study region, Sun and Liu (2012) related periods of low precipitation to the solar minimums since $1063 \mathrm{CE}$. To investigate whether such relationships existed in our reconstructed series, we considered two datasets of solar activities: a 9300-year record of total solar irradiance (TSI) based on cosmogenic radionuclide 10Be production with a 5-year temporal resolution (as differences from the solar cycle minimum of $1366.57 \mathrm{~W} \mathrm{~m}^{-2}$ in 1986 in 40-year running means and resampled to 5-year intervals) (Steinhilber et al., 2009) and a 2001-year record of annual solar forcing estimated from multiple proxies (Crowley, 2000; Jones and Mann, 2004).

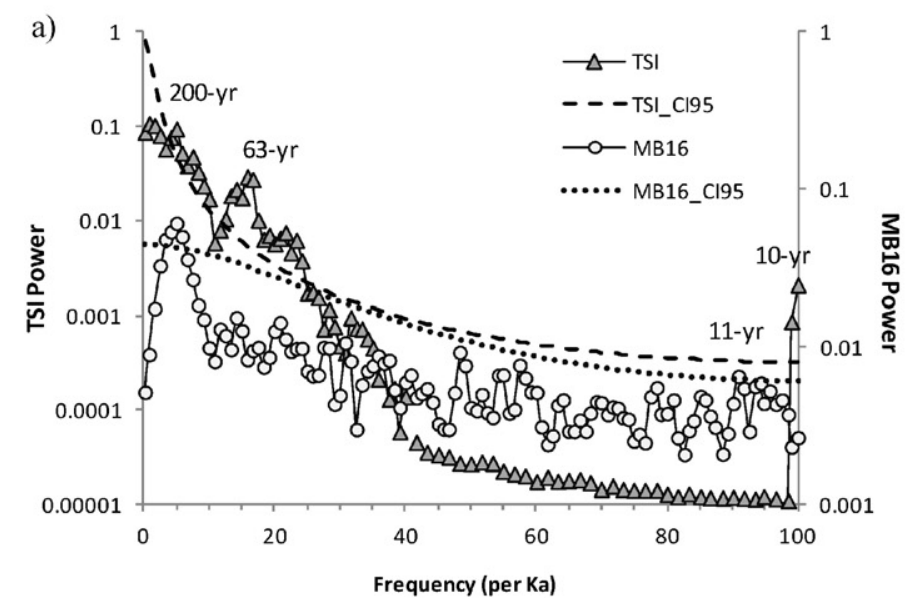

The reconstructed MB16 series was resampled into 5-year means that were centered on the 2nd and 7th years of each decade to match the TSI data. When the 5-year MB16 and 31-year moving averages were plotted against the solar activity series, there seemed to be a positive relationship at the decadal to multi-decadal scales (Fig. 8), especially for the past 1000 years or so. We calculated correlations between the reconstructed MB16 and the records of solar activities and found weak but statistically significant positive correlations (Table 6), confirming the pattern observed in Fig. 8.

A further analysis, however, revealed that the relationships were not robust through time, as indicated by the correlation coefficients between the 5-year means of MB16 and TSI for individual 300-year time blocks ( $\mathrm{N}=60$ for each run) during $842 \mathrm{BCE}-2002 \mathrm{CE}$. It can be seen that positive correlations dominated for the latest 900 years and were statistically significant in the most recent 600 years $\left(\mathrm{N}_{\text {Effective }}=23\right.$ with critical $r^{*}= \pm 0.4133$ ). This conformed with the findings by Sun and Liu (2012) relating droughts in the northeastern Tibetan Plateau to the solar minimums. The correlation was then reverted to negative (though not statistically significant) for most of the earlier periods (Fig. 8b). This led us to speculate that the variation patterns in the MB16 and solar activity series may not be concurrent and there might be cyclic patterns in either or both series with variable wavelengths. We also investigated the cross-correlations between the MB16 and solar activity series with different lags and the results are presented in the Supplementary Material (SM Fig. 4).

To examine the cyclic patterns in the MB16 and solar activity series and how such patterns varied over time, we first performed power spectral analysis on the reconstructed MB16 and solar activity series using both the 5-year and annual data. We found that the 5year MB16 series had 200-year and 11-year cycles, both with statistical significance and matching the $\sim 200$-year and $\sim 10$-year cycles in the TSI series, but not the 63-year cycle in TSI (Fig. 9a). For the annual data, however, the only matching pattern between the MB16 and solar forcing series was the $\sim 200$-year cycle (Fig. 9b), although the 5.5-year cycle in MB16 should match the 11-year sunspot cycle. The solar forcing series has many more low-frequency cyclic patterns with statistical significance than the 5-year TSI series, while most significant patterns in the MB16 series were in the high-frequency domain (not fully displayed in Fig. 9b). The differences between Fig. 9a and b were probably caused by resampling/averaging and the change in the data periods as the cyclic patterns varied in the temporal domain.

Other studies have found various cyclic patterns in millennium-long tree ring records (Lindholm et al., 2011; Ogurtsov et al., 2005; Wilson et al., 2007). An earlier study by Raspopov et al. (2008) suggested that tree ring data from central Asia to northeastern Tibetan Plateau

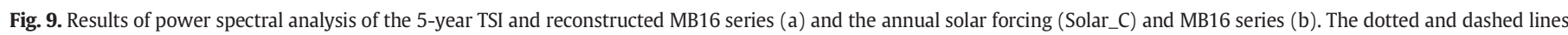

represent the $95 \%$ confidence level.

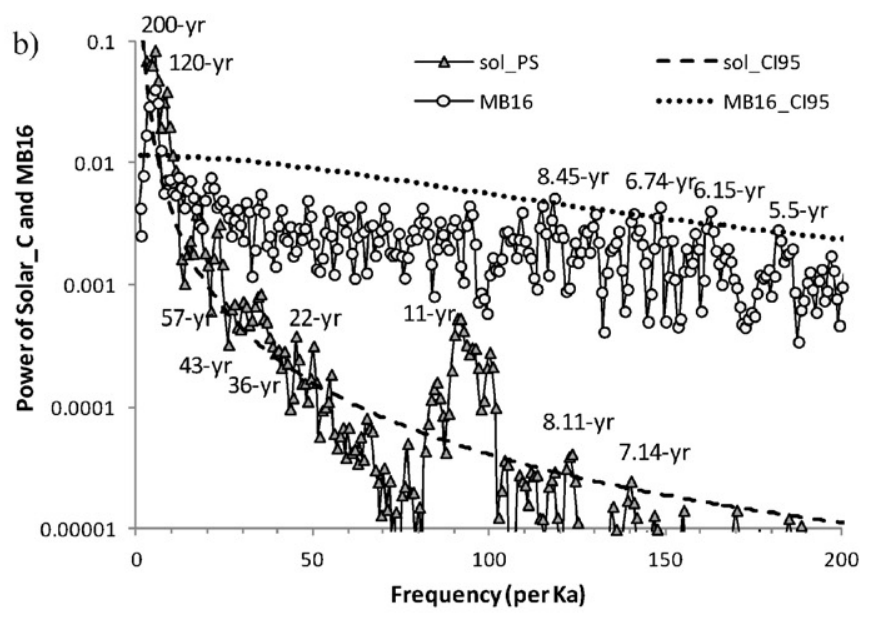



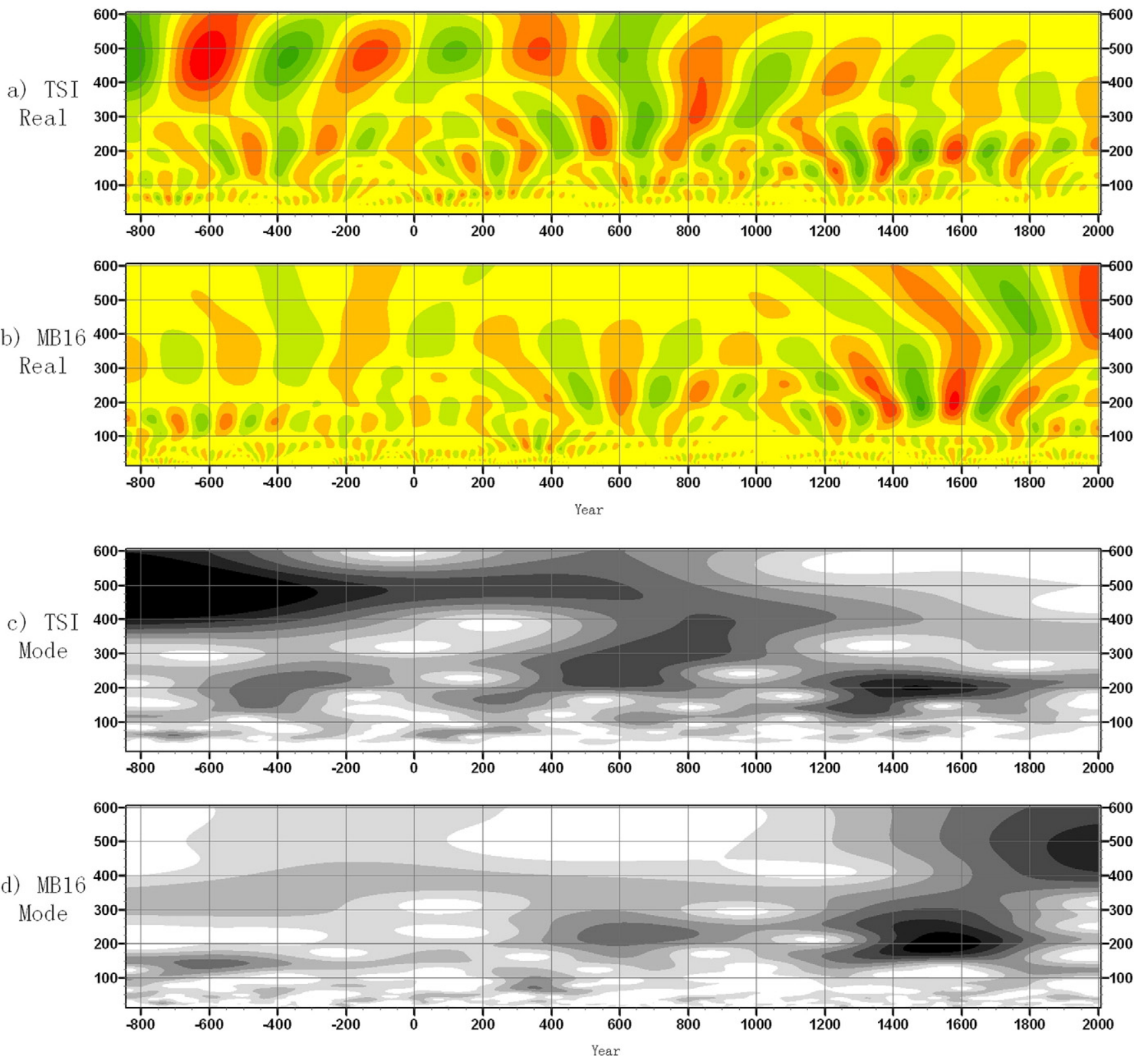

Fig. 10. Results of wavelet analysis: the real components of the wavelet spectrums of TSI (a) and MB16 (b) series (5-year data), and the modes of TSI (c) and MB16 (d).

(including our study region) contained signals of quasi-200-year cycles that may match the 210 -year de Vries solar cycle during the past $1000+$ years. In order to investigate temporal variation in the cyclic patterns in both the MB16 and solar activity (TSI) series, we performed wavelet analysis on these two series (Fig. 10). The plots of the real components of the two series (Fig. 10a and b) show that both series had relatively persistent cyclic variation patterns with $~ 200$-year wavelengths since $400 \mathrm{CE}$. Before $400 \mathrm{CE}$, however, the cyclic patterns in the BM16 series shifted toward shorter cycles (between 100-year and 200-year wavelengths in combination with weaker cyclic patterns of 300-400year wavelengths) (Fig. 10b), while those in the TSI series still fluctuated around the 200-year wavelength during this period (Fig. 10a). For the TSI series, longer-wavelength cyclic patterns (500-year cycles) occurred in the early period and then shifted to 300-400-year wavelengths between $600 \mathrm{CE}$ and $1000 \mathrm{CE}$ (Fig. 10a); while for the MB16 series, these long cycles occurred in the most recent period (Fig. 10b). These patterns were also confirmed by the mode plots, showing the matching cyclic patterns at $\sim 200$ years between the two series (Fig. 10c and d). Since the $\sim 200$-year cycles seemed to represent the relatively persistent patterns in both series, we plotted the amplitudes of fluctuation of these patterns: the 210-year de Vries cycles in the TSI series and 200-year cycles in the MB16 series (Fig. 11). It was clear that the peak power values occurred during 1300-1700 CE, coinciding with the Little Ice Age (LIA), during which there was a very good match between the two series. Prior to $400 \mathrm{CE}$, the power level in MB16 reduced significantly while the power in TSI remained relatively high, although it was also reduced from the level during the LIA. Previous studies (e.g., Huang, 2003; Huang and Shao, 2005; Raspopov et al., 2008) have suggested that precipitation in this region had a positive response to solar forcing and clearly this coupling was persistent during the most recent 700-800 years. Around $1300 \mathrm{CE}$, however, there was a shift in the MB16 series to a shorter cycle, which caused the decoupling between the two series and the positive relationship abruptly changed to out-of-phase fluctuations. If a positive response of MB16 to solar activity is assumed, the TSI series had a lead of 50-130 years (between the peak-power years of the TSI and MB16 series) prior to $1000 \mathrm{CE}$, which was then reduced to nearly zero after $1400 \mathrm{CE}$ (Fig. 11). Similar variation patterns were also identified by Yang et al. 


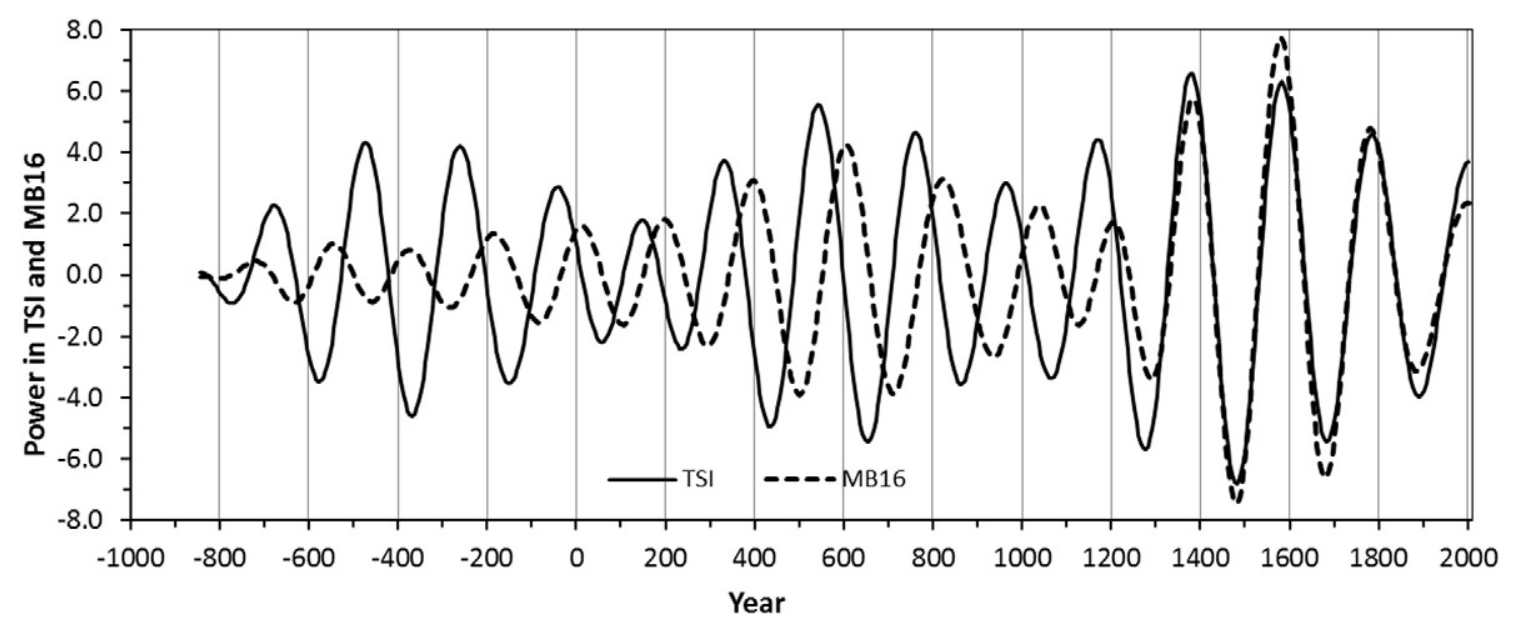

Fig. 11. Variations in the power of the 200-year cycles in MB16 and 210-year cycles in TSI.

(2014), although the cyclic patterns between the two reconstructed series seemed to differ prior to $1 \mathrm{CE}$. Without fully understanding the physical processes that actually produced such relationships and caused the changes over time, it is difficult to reach any final conclusions at this point.

\section{Conclusions}

In this study, we employed a monthly water balance model to characterize the average growth environment for the sampling sites of Qilian junipers near Delingha of the northeastern Tibetan Plateau. Then the model simulated January-June moisture balance was reconstructed using a 3585-year tree-ring width chronology, producing 2847 years of reconstruction from 843 BCE to 2004 CE. The long-term average moisture balance of $-61.9 \mathrm{~mm}$ indicates that trees growing on the mountains of the eastern Qaidam Basin are under conditions of persistent water shortage during the first half of year, which limits growth rates in this semi-arid region. In the meantime, this reconstructed series revealed centennial-scale drought periods during 381-277 BCE, 425-520 CE, 1108-1212 CE, 1428-1516 CE, and 1634-1743 CE, and allowed us to determine the return interval of the 1918 drought to be $\sim 950$ years.

Long series of climatic proxies offer the opportunities to explore potential relations of regional climate variability with various forcing mechanisms, such as monsoon intensity and solar activity, and to assess the temporal robustness of these relations. Such analyses are extremely valuable in identifying the nature of the relationships and then to reveal possible causation linkages. In our study, statistically significant negative correlations were found between the reconstructed moisture balance series and high-resolution Asian monsoon proxies based on stable isotopes in stalagmites. We also identified a positive correlation between the reconstructed moisture balance and solar activity - better moisture conditions during periods with higher solar irradiance, especially for the period since 1300 CE. Of the known cyclic patterns in solar activity, we found a consistently matching pattern at the $\sim 200$ year wavelength in the reconstructed moisture balance series to the 210-year de Vries solar cycle. Prior to 1000 CE, the solar cycles led the cycles in the moisture balance series. For the latest 700-800 years, however, the two series displayed much synchronized in-phase variation patterns. Clearly not all phenomena examined in this study have explanations at this point. For long-term climatic change studies, tree ring data have provided invaluable information on variation patterns of climate in the past, as illustrated in this study. However, we could still only focus on the variation patterns up to the centennial scale since the median segment length was 521 years in the 3585-year long chronology (Shao et al., 2010). Further efforts should continue to look for tree ring samples, preferably from subfossil and/or archaeological wood, with long segment lengths.

\section{Acknowledgements}

This study was in part supported by grants from the Chinese Academy of Sciences (grant XDA05080201), Chinese National Natural Science Foundation (grant 41471170), and University of San Diego (FRG 201011, 2012-13, and 2013-2014). The authors thank all parties involved in the fieldwork of sampling, lab work of sample processing and measurement, and other tasks leading to the final construction of the tree ring chronology used in this study. The authors are grateful to Dr. Paul Sheppard who graciously provided us with the reconstructed Dulan precipitation series for comparison, and Dr. Christopher Daly for the PRISM precipitation data of the Tibetan Plateau used in this study. The authors also thank the two anonymous reviewers and the editor who provided constructive comments and suggestions that significantly improved the manuscript.

\section{Appendix A. Supplementary material}

Supplementary material to this article can be found online at http:// dx.doi.org/10.1016/j.gloplacha.2016.04.010.

\section{References}

Barry, R.G., 1992. Mountain Weather and Climate. Routledge, New York (392 pp.). Black, P.E., 1996. Watershed Hydrology. second ed. Ann Arbor Press, Chelsea, Michigan (449 pp.).

Bretherton, C.S., Widmann, M., Dymnikov, V.P., Wallace, J.M., Blade, I., 1999. The effective number of spatial degrees of freedom of a time-varying field. J. Clim. 12 (7), 1990-2009.

Cheng, G.D., Wu, T.H., 2007. Responses of permafrost to climate change and their environmental significance, Qinghai-Tibet Plateau. J. Geophys. Res. Earth Surf. 112 (F2).

Cook, E.R., et al., 2010a. Asian monsoon failure and megadrought during the last millennium. Science 328 (5977), 486-489.

Cook, E.R., et al., 2010b. Megadroughts in North America: placing IPCC projections of hydroclimatic change in a long-term palaeoclimate context. J. Quat. Sci. 25 (1), 48-61.

Crowley, T.J., 2000. Causes of climate change over the past 1000 years. Science 289 (5477), 270-277.

Dai, A., Trenberth, K.E., Qian, T.T., 2004. A global dataset of Palmer drought severity index for 1870-2002: relationship with soil moisture and effects of surface warming. J. Hydrometeorol. 5 (6), 1117-1130.

Daly, C., Neilson, R.P., Phillips, D.L., 1994. A statistical-topographic model for mapping climatological precipitation over mountainous terrain. J. Appl. Meteorol. 33 (2), $140-158$.

Daly, C., Gibson, W., Hannaway, D., Taylor, G., 2000. Development of new climate and plant adaptation maps for China. Proceedings of the 12th Conference on Applied Climatology, May 8-11, pp. 62-65.

Daly, C., et al., 2008. Physiographically sensitive mapping of climatological temperature and precipitation across the conterminous United States. Int. J. Climatol. 28 (15), 2031-2064. 
Ding, Y., Wang, Z., 2008. A study of rainy seasons in China. Meteorolog. Atmos. Phys. 100, $121-138$.

Fan, Z.X., Brauning, A., Cao, K.F., Zhu, S.D., 2009. Growth-climate responses of highelevation conifers in the central Hengduan Mountains, southwestern China. For. Ecol. Manag. 258 (3), 306-313.

Fritts, H.C., 1976. Tree Rings and Climate. Academic Press, London (567 pp.).

Hahn, D.G., Shukla, J., 1976. An apparent relationship between Eurasian snow cover and Indian monsoon rainfall. J. Atmos. Sci. 33, 2461-2462.

Hijmans, R.J., Cameron, S.E., Parra, J.L., Jones, P.G., Jarvis, A., 2005. Very high resolution interpolated climate surfaces for global land areas. Int. J. Climatol. 25 (15), 1965-1978.

Hu, C.Y., et al., 2008. Quantification of Holocene Asian monsoon rainfall from spatially separated cave records. Earth Planet. Sci. Lett. 266 (3-4), 221-232.

Huang, L., 2003. Study on Characteristics and Mechanisms of Millennial Precipitation Variation in Northeast Qinghai-Tibetan Plateau, China (Ph. D thesis Thesis). (113 pp.).

Huang, L., Shao, X., 2005. Precipitation variation in Delingha, Qinghai, and solar activity over the last 400 years. Quat. Sci. 25 (2), 184-192.

Hughes, M.K., 2011. Dendroclimatology in high-resolution paleoclimatology dendroclimatology. In: Hughes, M.K., Swetnam, T.W., Diaz, H.F. (Eds.), Developments in Paleoenvironmental Research. Springer Netherlands, pp. 17-34.

Hutchinson, M.F., 2004. ANUSPLIN Version 4.3. Center for Resource and Environmental Studies, The Australian National University, Canberra, Australia.

Jones, P.D., Mann, M.E., 2004. Climate over past millennia. Rev. Geophys. 42 (2), 1-42.

Li, C., Yanai, M., 1996. The onset and interannual variability of the Asian summer monsoon in relation to land-sea thermal contrast. J. Clim. 9, 358-375.

Li, X., Cheng, D., Jin, H., Kang, E., Che, T., Jin, R., Wu, L., Nan, Z., Wang, J., Shen, Y., 2008. Cryospheric change in China. Glob. Planet. Chang. 62 (3-4), 210-218.

Lindholm, M., Jalkanen, R., Salminen, H., Aalto, T., Ogurtsov, M., 2011. The heightincrement record of summer temperature extended over the last millennium in Fennoscandia. The Holocene 21 (2), 319-326.

Liu, X.D., Chen, B.D., 2000. Climatic warming in the Tibetan Plateau during recent decades. Int. J. Climatol. 20 (14), 1729-1742.

Liu, X., Yanai, M., 2002. Influence of Eurasian spring snow cover on Asian summer rainfall. Int. J. Climatol. 22, 1075-1089.

Liu, X.D., Yin, Z.-Y., Shao, X.M., Qin, N.S., 2006. Temporal trends and variability of daily maximum and minimum, extreme temperature events, and growing season length over the eastern and central Tibetan Plateau during 1961-2003. J. Geophys. Res.Atmos. 111 (D19)

Mather, J.R., 1978. The Climatic Water Balance in Environmental Analysis. D.C. Heath and Company, Lexington, Massachusetts (239 pp.).

McCabe, G.J., Markstrom, S.L., 2007. A monthly water-balance model driven by a graphical user interface. U.S. Geological Survey Open-File Report 2007-1088.

Michaelsen, J., 1987. Cross-validation in statistical climate forecast models. J. Clim. Appl. Meteorol. 26, 1589-1600.

Ogurtsov, M., Helama, S., Eronen, M., Lindholm, M., 2005. Centennial-to-millennial fluctuations in July temperatures in North Finland as recorded by timberline tree rings of Scots pine. Quat. Res. 63 (2), 182-188.

Palmer, W.C., 1965. Meteorological Drought. US Department of Commerce, Weather Bureau Washington, DC, USA.

Peng, J.F., et al., 2007. Horizontal variations of climatic response of Qilian juniper (Juniperus przewalskii) in the Anyemaqen mountains. Acta Geograph. Sin. 62 (7), 742-752.

Qin, N.S., et al., 2003. Climate change over southern Qinghai Plateau in the past 500 years recorded in Sabina tibetica tree rings. Chin. Sci. Bull. 48 (22), 2483-2487.

Raspopov, O.M., et al., 2008. The influence of the de Vries ( similar to 200-year) solar cycle on climate variations: results from the Central Asian Mountains and their global link. Palaeogeogr. Palaeoclimatol. Palaeoecol. 259 (1), 6-16.

Routson, C.C., Woodhouse, C.A., Overpeck, J.T., 2011. Second century megadrought in the Rio Grande headwaters, Colorado: how unusual was medieval drought? Geophys. Res. Lett. 38.

Shao, X.M., et al., 2005. Reconstruction of precipitation variation from tree rings in recent 1000 years in Delingha, Qinghai. Sci. China Ser. D Earth Sci. 48 (7), 939-949.

Shao, X., et al., 2007. A 3500-year master tree-ring dating chronology from the northeastern part of the Qaidam Basin. Quat. Sci. 27 (4), 477-485 (in Chinese).

Shao, X.M., et al., 2009. A 3585-year ring-width dating chronology of Qilian juniper from the northeastern Qinghai-Tibetan Plateau. IAWA J. 30 (4), 379-394.

Shao, X., et al., 2010. Climatic implications of a 3585-year tree-ring width chronology from the northeastern Qinghai-Tibetan Plateau. Quat. Sci. Rev. 29 (17-18), 2111-2122.

Sheppard, P.R., et al., 2004. Annual precipitation since 515 BC reconstructed from living and fossil juniper growth of northeastern Qinghai Province, China. Clim. Dyn. 23 (7-8), 869-881.

Shi, X.H., et al., 2010. May-June mean maximum temperature change during 1360-2005 as reconstructed by tree rings of Sabina tibetica in Zaduo, Qinghai Province. Chin. Sci. Bull. 55 (26), 3023-3029.

Sinha, A., et al., 2011. A global context for megadroughts in monsoon Asia during the past millennium. Quat. Sci. Rev. 30 (1-2), 47-62.
Stahle, D.W., Fye, F.K., Cook, E.R., Griffin, R.D., 2007. Tree-ring reconstructed megadroughts over North America since AD 1300. Clim. Chang. 83 (1-2), 133-149.

Steinhilber, F., Beer, J., Frohlich, C., 2009. Total solar irradiance during the Holocene. Geophys. Res. Lett. 36.

Sun, J.Y., Liu, Y., 2012. Tree ring based precipitation reconstruction in the south slope of the middle Qilian Mountains, northeastern Tibetan Plateau, over the last millennium. J. Geophys. Res.-Atmos. 117, D08108. http://dx.doi.org/10.1029/2011jd017290.

Thornthwaite, C.W., Mather, J.R., 1955. The water balance. Publications in Climatology, 8. Drexel Institute of Technology, New Jersey.

Wang, J., 1993. Qilian juniper. In: Editing Committee of Qinghai Forest (Ed.), Qinghai Forest. Chinese Forestry Publishing House (in Chinese), Beijing, China, pp. 230-240.

Wang, Y.J., et al., 2005. The Holocene Asian monsoon: links to solar changes and North Atlantic climate. Science 308 (5723), 854-857.

Wang, G.X., Li, Y.S., Hu, H.C., Wang, Y., 2008. Synergistic effect of vegetation and air temperature changes on soil water content in alpine frost meadow soil in the permafrost region of Qinghai-Tibet. Hydrol. Process. 22 (17), 3310-3320.

Wang, G.X., Bai, W., Li, N., Hu, H.C., 2011. Climate changes and its impact on tundra ecosystem in Qinghai-Tibet Plateau, China. Clim. Chang. 106 (3), 463-482.

Wigley, T.M.L., Briffa, K.R., Jones, P.D., 1984. On the average value of correlated time series, with applications in dendroclimatology and hydrometeorology. J. Clim. Appl. Meteorol. 23 (2), 201-213.

Wilson, R., Wiles, G., D'Arrigo, R., Zweck, C., 2007. Cycles and shifts: 1300 years of multidecadal temperature variability in the Gulf of Alaska. Clim. Dyn. 28 (4), 425-440.

Woodward, F.I., Lomas, M.R., Kelly, C.K., 2004. Global climate and the distribution of plant biomes. Philos. Trans. R. Soc., B 359, 1465-1476.

Wu, Y., 1990. Precipitation in the Tibetan Plateau. In: Dai, J., et al. (Eds.), Climate of the Tibetan PlateauA Series of Books of China's Climate. Meteorology Publishing House, Beijing, China, pp. 171-196.

Wu, T.-W., Qian, Z.-A., 2003. The relation between the Tibetan winter snow and Asian summer monsoon and rainfall: an observational investigation. J. Clim. 16, 2038-2051.

Wu, G.X., et al., 2007. The influence of mechanical and thermal forcing by the Tibetan Plateau on Asian climate. J. Hydrometeorol. 8 (4), 770-789.

Xu, C.Y., Singh, V., 1998. A review on monthly water balance models for water resources investigations. Water Resour. Manag. 12 (1), 20-50.

Yanai, M., Li, C.F., 1994. Mechanism of heating and the boundary-layer over the Tibetan Plateau. Mon. Weather Rev. 122 (2), 305-323.

Yanai, M.H., Li, C.F., Song, Z.S., 1992. Seasonal heating of the Tibetan Plateau and its effects on the evolution of the Asian summer monsoon. J. Meteorol. Soc. Jpn. 70 (1B), 319-351.

Yang, B., et al., 2014. A 3500-year tree-ring record of annual precipitation on the northeastern Tibetan Plateau. Proc. Natl. Acad. Sci. U. S. A. 111 (8), 2903-2908.

Yao, T., Pu, J., Lu, A., Wang, Y., Yu, W., 2007. Recent glacial retreat and its impact on hydrological processes on the Tibetan Plateau, China, and surrounding regions. Arct. Antarct. Alp. Res. 39 (4), 642-650.

Yeh, T.C., Gao, Y.X., 1979. The Meteorology of the Qinghai-Xizang (Tibet) Plateau (in Chinese). Science Press, Beijing (278 pp.).

Yin, Z.-Y., Shao, X.M., Qin, N.S., Liang, E., 2008. Reconstruction of a 1436-year soil moisture and vegetation water use history based on tree-ring widths from Qilian junipers in northeastern Qaidam Basin, northwestern China. Int. J. Climatol. 28 (1), 37-53.

Zhang, Q.B., Cheng, G.D., Yao, T.D., Kang, X.C., Huang, J.G., 2003. A 2326-year tree-ring record of climate variability on the northeastern Qinghai-Tibetan Plateau. Geophys. Res. Lett. 30 (14), 1739-1741.

Zhang, Y., Li, T., Wang, B., 2004. Decadal change of the spring snow depth over the Tibetan Plateau: the associated circulation and influence on the East Asian summer monsoon. J. Clim. 17, 2780-2793.

Zhang, P.Z., et al., 2008. A test of climate, sun, and culture relationships from an 1810-year Chinese cave record. Science 322 (5903), 940-942.

Zhang, Y., et al., 2011. Characteristics of extreme droughts inferred from tree-ring data in the Qilian Mountains, 1700-2005. Clim. Res. 50 (2-3), 141-159.

Zhao, L., et al., 2004. Changes of climate and seasonally frozen ground over the past 30 years in Qinghai-Xizang (Tibetan) Plateau, China. Glob. Planet. Chang. 43 (1-2), $19-31$.

Zhao, P., Zhou, Z., Liu, J., 2007. Variability of Tibetan spring snow and its associations with the hemispheric extratropical circulation and East Asian summer monsoon rainfall: an observation investigation. J. Clim. 20, 3942-3955.

Zhao, D.S., Wu, S.H., Yin, Y.H., Yin, Z.Y., 2011. Vegetation distribution on Tibetan Plateau under climate change scenario. Reg. Environ. Chang. 11 (4), 905-915.

Zheng, D., 1996. The system of physico-geogrpahical regions of the Qinghai-Xizang (Tibetan) Plateau. Sci. China Ser. D Earth Sci. 39 (4), 410-417.

Zhu, H.Z., Luo, T.X., Daly, C., 2003. Validation of simulated grid data sets of China's temperature and precipitation with high spatial resolution. Geogr. Res. 22 (3), 349-359.

Zhu, H.F., Shao, X.M., Yin, Z.Y., Huang, L., 2011. Early summer temperature reconstruction in the eastern Tibetan Plateau since AD 1440 using tree-ring width of Sabina tibetica. Theor. Appl. Climatol. 106 (1-2), 45-53. 